\title{
FGF8 induces chemokinesis and regulates condensation of mouse nephron progenitor cells
}

\author{
Abhishek Sharma ${ }^{1,2, *}$, Marco Meer ${ }^{3,4},{ }^{*}$, Arvydas Dapkunas ${ }^{5}$, Anneliis Ihermann-Hella ${ }^{5}$, Satu Kuure ${ }^{5,6}$, Seppo \\ Vainio $^{1,2,7,8,9, \ddagger}$, Dagmar Iber ${ }^{3,4, \ddagger}$, and Florence Naillat ${ }^{1,2, \ddagger}$ \\ ${ }^{1}$ Faculty of Biochemistry and Molecular Medicine, University of Oulu, Finland \\ ${ }^{2}$ Biocenter Oulu, Finland \\ ${ }^{3}$ Department of Biosystems, Science and Engineering, ETH Zürich, Switzerland \\ ${ }^{4}$ Swiss Institute of Bioinformatics, Switzerland \\ ${ }^{5}$ HiLIFE and Research Programs Unit, Faculty of Medicine, University of Helsinki, Finland \\ ${ }^{6}$ GM-Unit, LAC/ HiLIFE, and Medicum, University of Helsinki, Finland \\ ${ }^{7}$ Infotech Oulu, Finland \\ ${ }^{8}$ Borealis Biobank, Oulu, Finland \\ ${ }^{9}$ Kvantum Institute, University of Oulu, Oulu, Finland
}

\begin{abstract}
Kidneys develop via iterative branching of the ureteric epithelial tree and subsequent nephrogenesis at the branch points. Nephrons form in the cap mesenchyme as the metanephric mesenchyme (MM) condenses around the epithelial ureteric buds (UBs). Previous work demonstrated that FGF8 is important for the survival of nephron progenitor cells (NPCs), and early deletion of Fgf8 leads to the cessation of nephron formation, which results in post-natal lethality. We now reveal a novel function of FGF8. By combining transgenic mouse models, quantitative imaging assays, and data-driven computational modelling, we show that FGF8 has a strong chemokinetic effect and that this chemokinetic effect is important for the condensation of NPCs to the UB. The computational model shows that the motility must be lower close to the UB to achieve NPC attachment. We conclude that the FGF8 signalling pathway is crucial for the coordination of NPCs behaviour to the UB. Chemokinetic effects have been described also for other FGFs and may be relevant more generally for the formation of mesenchymal condensations.
\end{abstract}

\section{Introduction}

Mesenchymal condensation is an essential step in kidney development for the early formation of nephrons. This mechanism consists of reciprocal interactive signalling between mesenchymal cells and their surrounding, the epithelial and stromal cells [1-3]. In addition to reciprocal signalling, intercellular interactions, cellular morphogenesis, i.e. apoptosis or adhesion, and cell migration play an essential role during the establishment of mesenchymal condensation [4-6]. Cell migration can be influenced by chemical, thermal, galvanic, electrical, gravitational, or mechanical stimuli, or combinations of these phenomena. A stimulus can cause a tactic response, in which cell movement is directed to the location of the stimulus, or a kinetic response, i.e., random locomotion, in which the magnitude of the response depends on the intensity of the stimulus [7]. Particularly in the presence of chemical gradients, cells can show strong chemotactic or chemokinetic responses. In mice, around embryonic days 1111.5 (E11-E11.5), mesenchymal condensation in the nephrogenic niche of the developing kidney results in the formation of the cap mesenchyme (CM) $[2,8]$. At the same time, nephron progenitor cells (NPCs) from the CM migrate in a stochastic fashion between the top (or tip region) of the epithelial ureteric bud (UB) and the bottom (or trunk region) (Figure 1) [9-11]. NPC fate is region-specific and requires reciprocal signals between the UB and the surrounding mesenchymal and stromal cells (Figure 1) $[1,2,11-16]$. NPCs that are located in the tip region of the UB maintain their progenitor state and are thus called true

\footnotetext{
*These authors contributed equally to this work.

${ }^{\ddagger}$ Corresponding authors: Florence.Naillat@Oulu.fi,

Dagmar.Iber@bsse.ethz.ch, Seppo.Vainio@Oulu.fi
}

nephron progenitor cells (tNPCs) (Figure 1) [10, 14, 17]. NPCs that migrate downwards to the trunk region are further primed by factors from the UB, becoming committed NPCs (cNPCs) $[2,12,14,15]$. A fraction of the cNPCs in the trunk region starts to form a pretubular aggregate (PTA), initiating nephron formation $[2,9,11,12,18]$. The regulation of NPC fates, migration, and priming have been studied intensely [2, 3, 19], but the cellular mechanism underlying the condensation of NPCs to the UB has not yet been elucidated. Various signaling factors, receptors, and extracellular matrix molecules have been suggested to play a role in NPC condensation (Figure 1), but its key regulators remain elusive $[9,20-22]$.

Fibroblast growth factors (FGFs) are a family of signaling proteins that govern different aspects of kidney development, including UB branching and maintenance of NPCs [24]. Deletion or mutations in either FGFs or their receptors (FGFRs) can lead to either kidney agenesis or disorders [24]. FGF8 is expressed in the mesenchyme and is required for both the regulation of downstream genes involved in PTA formation and cell survival [12, 25-27]. Deletion of Fgf8 from kidney primordia leads to a lack of mature nephrons, and eventually to lethality within $24 \mathrm{hrs}$ of birth [25]. The failure of nephron maturation has been attributed to the lack of expression of Wnt4 and Lim1 (Lhx1), both of which are crucial for MET [25]. Culturing isolated MM from kidneys lacking Fgf8 along with a WNT source (embryonic spinal cord), however, failed to initiate nephrogenesis [25, 26], supporting the notion that WNT4 and FGF8 work independently. Further, when ectopic FGF8 was added in combination with a WNT source, MMs lacking Fgf8 expression formed PTAs [25]. These results indicate that FGF8 enhances WNT4 ex- 
bioRxiv preprint doi: https://doi.org/10.1101/2022.02.07.478973; this version posted February 7, 2022. The copyright holder for this preprint (which was not certified by peer review) is the author/funder, who has granted bioRxiv a license to display the preprint in perpetuity. It is made available under aCC-BY-NC-ND 4.0 International license.

Top
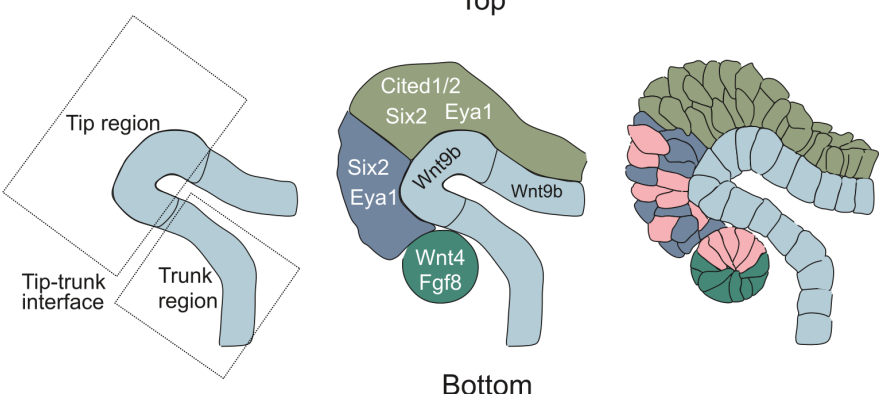

Ureteric Bud

tNPCs

cNPCs

PTA

Fgf8 expressing cells

Figure 1: Cartoon depicting the UB and the CM nephron progenitor population during early kidney development. tNPCs express Cited1/2, Six2 and Eya1, while cNPCs lose Cited1/2 expression upon priming by Wnt9b from the UB. A subset of cNPCs continues to form a PTA at the tip-trunk interface. Schematic based on [10, 17, 23].

pression in PTAs but also suggest that FGF8 and WNT4 work independently. As little is known about the specific role of FGF8 during cap mesenchyme formation, we further characterise its specific role to demonstrate that the FGF8 signal coordinates NPC migration during mesenchymal condensation.

\section{Results}

\section{Without the expression of $F g f 8$, cap mesenchyme formation and attachment of CM cells to the UB are impaired}

When the kidney develops from the posterior intermediate mesoderm [28], the Brachyury/ $T$ gene is required for the formation of the posterior mesoderm and axial development [29]. Hence, Brachyury $/ T^{C r e}$-mediated deletion leads to the deletion of Fgf8 in both epithelial and mesenchymal compartments of the developing kidney [25, 28, 29]. To examine more closely the involvement of FGF8 in kidney development we stained mutant kidneys $\left(F g f 8^{n / c} ; T^{C r e}\right)$ with SIX2, a known NPC marker $[2,3]$. In $F g f 8^{n / c} ; T^{C r e}$ mutant kidneys, we found that the $S I X 2^{+}$ cell population was diminished and less condensed than in the controls (Figure 2A,B). The reduced cell number has previously been attributed to increased cell death in Fgf8-deficient kidneys [25]. We hypothesized that the absence of FGF8 signaling additionally leads to decreased cell motility and consequent failure of cell condensation and eventually the termination of nephrogenesis. To test this hypothesis, we first investigated whether the failure of $S I X 2^{+}$cells to condensate would also occur in an in vitro culture assay. We used the Trowell culture method to culture $F g f 8^{n / c} ; T^{C r e}$ kidneys and littermate control kidneys. After 3 days of culture, corresponding to E16.5, we found that the $S I X 2^{+}$cells in mutant kidneys were significantly less condensed as compared to their littermate controls (Figure 2C-D). More specifically, we found that the CM in mutant kidneys was on average twice as thick as in the controls (Figure 2E). In accordance with this observation, the $S I X 2^{+}$cells in mutant kidneys were strongly dispersed within the niche (Figure $2 \mathrm{~F}$ ). We therefore wondered whether the number of $S I X 2^{+}$cells that are attached to the UB was also affected as a result. Attachment to the UB has previously been suggested to affect the differentiation capacity of mesenchymal cells [15]. We classified $S I X 2^{+}$ cells to be attached to the UB when their centroid position was closer to the UB tip than a threshold value of $17.4 \mu \mathrm{m}$, which corresponds to twice the median position of $S I X 2^{+}$cells that we measured in the controls (Figure $2 \mathrm{~F}$ ). Our choice of threshold value agrees well with the upper quartile of distances that were previously ascribed to the attached state $(15.2 \mu \mathrm{m},[9])$. We also found that the percentage of attached cells in our controls $(92 \%$, Figure $2 \mathrm{G}$ ) was in good agreement with what was previously found $(85 \%$, cf. Figure 5 source data of [9]). Finally, we found that in our Fgf8-deficient mutant kidneys the proportion of $S I X 2^{+}$cells that was attached to the UB tip was significantly lower than in the controls (Figure $2 \mathrm{G}$ ). Thus, as a next step, we wanted to investigate the effect of FGF8 on the $S I X 2^{+} \mathrm{NPC}$ population in more detail.

\section{FGF8 induces NPC aggregate formation in vitro and is required for $\mathrm{tNPC}$ maintenance}

The $S I X 2^{+}$NPCs dominate the CM population around the UB [30], and when these cells are primed as cNPCs, a subset of these cNPCs forms a PTA $[2,3]$. In an exhaustive study of secreted FGF family members which are required for the maintenance of the tNPC state, it has been suggested that FGF8 fails to maintain the true progenitor state of NPCs [31]. However, this study made use of a 2D monolayer culture, which differs from the 3D in vivo microenvironment of the developing kidney. Ihermann-Hella et al. and Dapkunas et al. have since developed a 3D culture system for NPCs [32, 33]. Much as in the 2D cultures, MM cells form aggregates when cultured with FGF2 in the $3 \mathrm{D}$ cultures $[32,34]$. To test whether NPCs would also condensate in response to FGF8, we cultured the dissociated NPCs from E11.5 kidneys in a 3D matrix along with FGF2 (positive control), or FGF8, or anti-FGF8 antibody to block any FGF8 secreted by MM cells. The chosen monoclonal anti-FGF8 antibody binds selectively to FGF8 in in vitro experiments (Supplementary Figure 1). From dissected E11.5 kidneys, MM was separated from UB, dissociated into single cell suspension, seeded in matrigel and cultured for 24 hours.

In response to both FGF2 and FGF8, the NPCs formed condensates and retained Six2 expression (Figure 3B,C), while both the control and NPCs treated with anti-FGF8 antibody lost SIX2 expression (Figure 3A,D, Supplementary Movie 1). We also found that the loss of SIX2 expression as a result of the absence of FGF8 (Figure 3A,D) was not completely due to cell death as more live cells were observed (Figure 3E). This suggests that FGF8 plays an additional role in NPC commitment along with its role in forming NPC condensates. To examine the differentiation stage of NPCs between tNPCs and cNPCs, a qPCR analysis of NPCs in the presence or absence of FGF8 was carried out. tNPC markers such as Cited2, Six2 and Eya1 were maintained by ectopic FGF8 (Figure 3F). To confirm that the results were not influenced by signals from the UB, the same experiment was carried out with fully dissociated MMs lacking UB. Similar results were obtained with retained tNPC markers when treated with ectopic FGF8 (Fig 3G). It has been reported that cross-talk between WNT and FGF signalling pathways is linked by modulation of phosphorylation of $G S K 3 \beta$ [35], but we did not observe this in our setting (Supplementary Figure 2). Finally, in wild type kidneys that were cultured in the presence of ectopic FGF8 (Trowell culture method), we could observe an expansion of the $S I X 2^{+}$population (Figure $3 \mathrm{H}$ ). In conclusion, our 3D culture matrix experiments suggest that FGF8 is required for both NPC condensation and tNPC maintenance.

\section{FGF8 elicits a chemokinetic response}

FGFs have been shown to act as chemoattractants that trigger a chemotactic response $[37,38]$, i.e., the migration of a cell along the concentration gradient of the chemoattractant. To determine how FGF8 affects NPC motility, we placed an FGF8 soaked bead in a $3 \mathrm{D}$ matrigel matrix containing MM cells from 
bioRxiv preprint doi: https://doi.org/10.1101/2022.02.07.478973; this version posted February 7, 2022. The copyright holder for this preprint (which was not certified by peer review) is the author/funder, who has granted bioRxiv a license to display the preprint in perpetuity. It is made available under aCC-BY-NC-ND 4.0 International license.
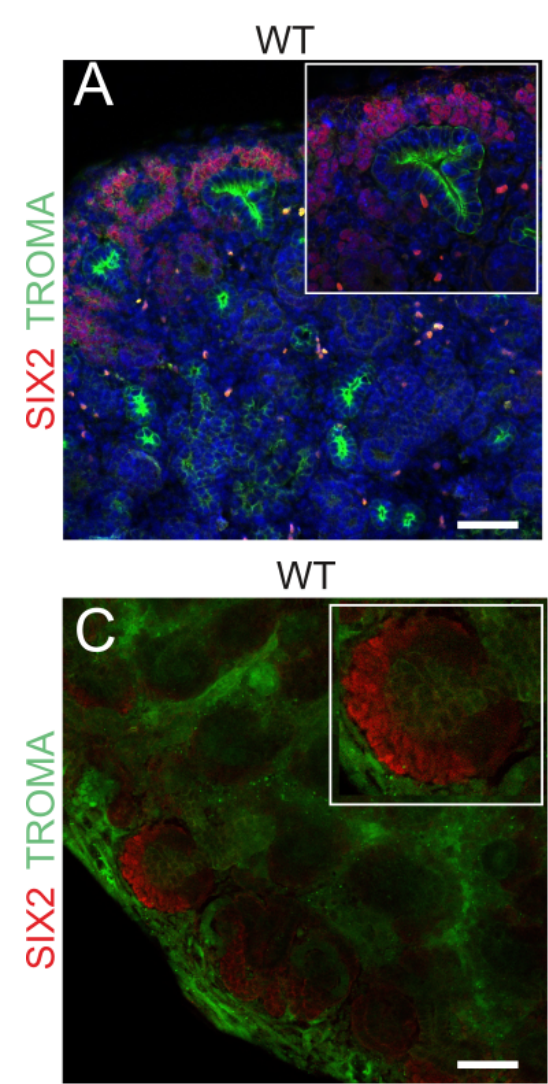

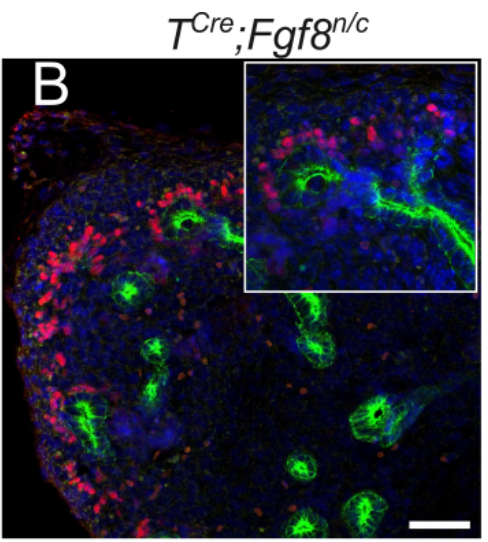

$T^{\mathrm{Cre}} ; \mathrm{Fgf8}^{\mathrm{n} / \mathrm{c}}$

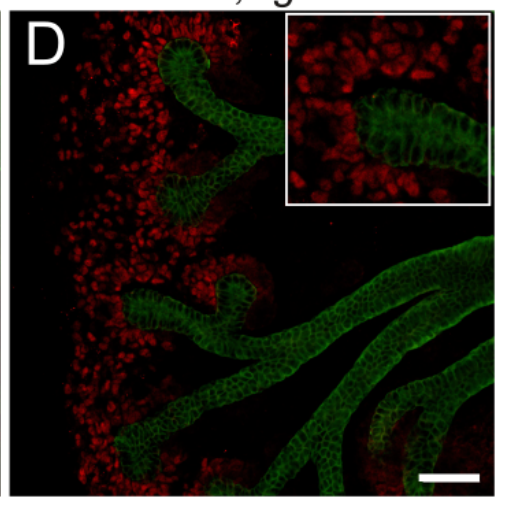

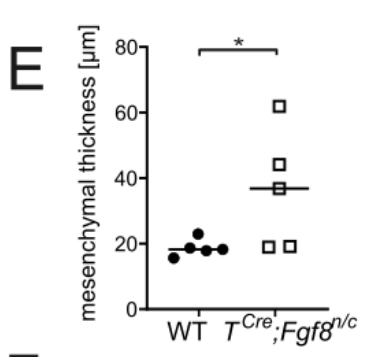

$F$
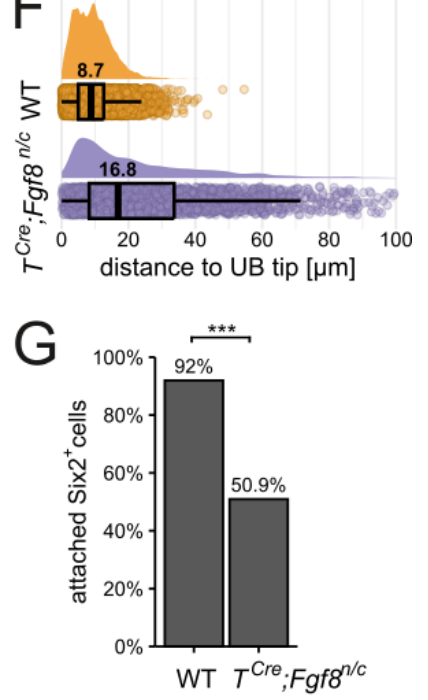

Figure 2: Impaired cap mesenchyme formation. (A-D) Kidneys were stained with SIX2 (NPCs, red), Troma-1 (UB, green) and DNA was counter stained with Hoechst33342 (Blue). Scale bars represent $100 \mu \mathrm{m}$. (A) E16.5 littermate control. (B) E16.5 kidneys where $F g f 8$ was deleted using $T^{C r e}$. (C) Littermate control E11.5 kidneys cultured in Trowell culture system. (D) E11.5 kidneys where Fgf8 was deleted using $T^{C r e}$ cultured in Trowell system. (B,D) NPCs did not form a condensed cap mesenchyme, but were scattered around the tip region of the UB as compared to the littermate controls (A,C), respectively. The inserts are higher magnification selections. (E) Cap mesenchymal thickness as the distance of the last layer of $\operatorname{Six} 2^{+}$cells from the UB tip of cultured E11.5 Fgf $8^{n / c} ; T^{C r e}$ kidneys. Statistics were performed in the kidneys $(\mathrm{n}=6)$ per sample, $p$ values were calculated using t-test, ${ }^{*} \mathrm{p}<0.05$. (F) Distributions of distance between centroids of $S i x 2^{+}$cells and UB tip in E16.5 Trowell cultured Fgf $8^{n / c}$; $T^{\text {Cre }}$ kidneys $(\mathrm{n}=13)$ and littermate controls $(\mathrm{n}=15)$, pooled data. Numbers above the boxplots represent median distances. (G) Percentage of $\mathrm{Six}^{+}$cells attached to the UB. Total number of cells (pooled data): 11425 (controls), $3214\left(\mathrm{Fg} f 8^{n / c} ; \mathrm{T}^{\mathrm{Cre}}\right)$. $S i x 2^{+}$cells were classified as attached to the UB when their centroid position was within a distance of $17.4 \mu \mathrm{m}$ from the UB, corresponding to twice the median position of Six $2^{+}$cells in the controls. Significance level: *** p $<0.001$.

E11.5 kidneys and tracked cells (Supplementary Movie 2). Cell tracking revealed that MM cells migrated significantly faster compared to the control bead experiments, but cellular motion was stochastic and lacked directionality (Figure 4; Supplementary Movie 2). This shows that FGF8 has mainly a chemokinetic effect, i.e., an impact on the speed of movement, rather than a chemotactic effect. Here, we note that we did not measure the FGF8 concentration profile and thus cannot exclude that meaningful gradients did not emerge due to rapid dispersion of FGF8 in matrigel. Previous measurements in zebrafish showed that the diffusion coefficient of FGF8 is high in aqueous environments [39]. The measured cell speeds $(4.6 \pm 0.5 \mu \mathrm{m} / \mathrm{h}$; Figure $4 \mathrm{~N})$ are comparable to those measured by others in the UB tip region $[9,40]$. Interestingly, in the presence of FGF 8 soaked beads, most cells formed large aggregates, resulting in a collective movement resembling swarm behaviour, which is reflected in the bifurcation of the track straightness measurements of FGF8 vs. control (Figure 4 E,F, Supplementary Movie 2). In the control bead experiments, only a few small aggregates were formed, presumably due to low levels of Fgf8 expression by some MM cells.In summary, we find that FGF8 triggers a chemokinetic response of MM cells from E11.5 kidneys. This observation of undirected cellular motility agrees with previous quantifications where MM cells were found to move semi-stochastic and swarming-like [9].

\section{A model based on FGF8-induced motility leads to robust condensation of NPCs}

We next thought to test the impact of FGF8-induced chemokinesis on NPC condensations at the UB using computational modelling. UB outgrowth starts at around E10.5 when the metanephric mesenchyme is in a diffuse, thickened state, inducing the patterning of the MM $[8,12,34,41-43]$. At around E11, diffuse weak expression of $F g f 8$ by MM cells coincides with the emergence of a well-defined cap mesenchyme [8, 12, 43]. Close to the UB, MM cells are rather immotile [9]. Interestingly, Sonic hedgehog (SHH), a repressor of Fgf8 expression, is secreted from UB cells during early nephrogenesis [39, 44]. The SHH gradient emanating from the UB likely results in the lower Fgf8 expression that is observed closer to the UB [45]. A gradient of autocrine FGF8 signaling and thus chemokinesis would be in agreement with the previous observation that cell speeds increase with distance from the UB [9]. In the same study, it was found that MM cells experience a subtle attraction towards the UB, indicating the presence of a chemotactic factor. WNT11 represents a likely candidate, as it is secreted already around E10.5-E11 by UB tip cells and is required for stable NPC-UB 
bioRxiv preprint doi: https://doi.org/10.1101/2022.02.07.478973; this version posted February 7, 2022. The copyright holder for this preprint (which was not certified by peer review) is the author/funder, who has granted bioRxiv a license to display the preprint in perpetuity. It is made available under aCC-BY-NC-ND 4.0 International license.

\section{SIX2/DAPI}

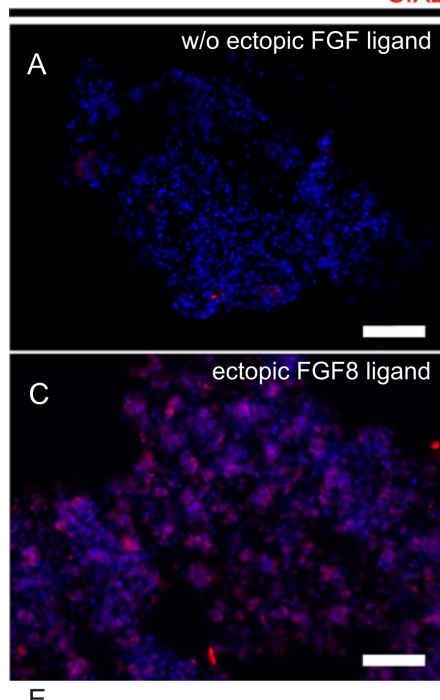

E

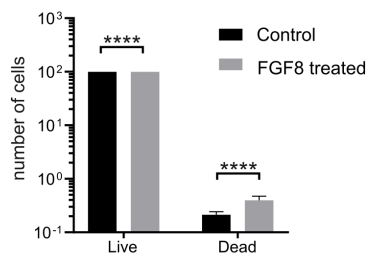

G
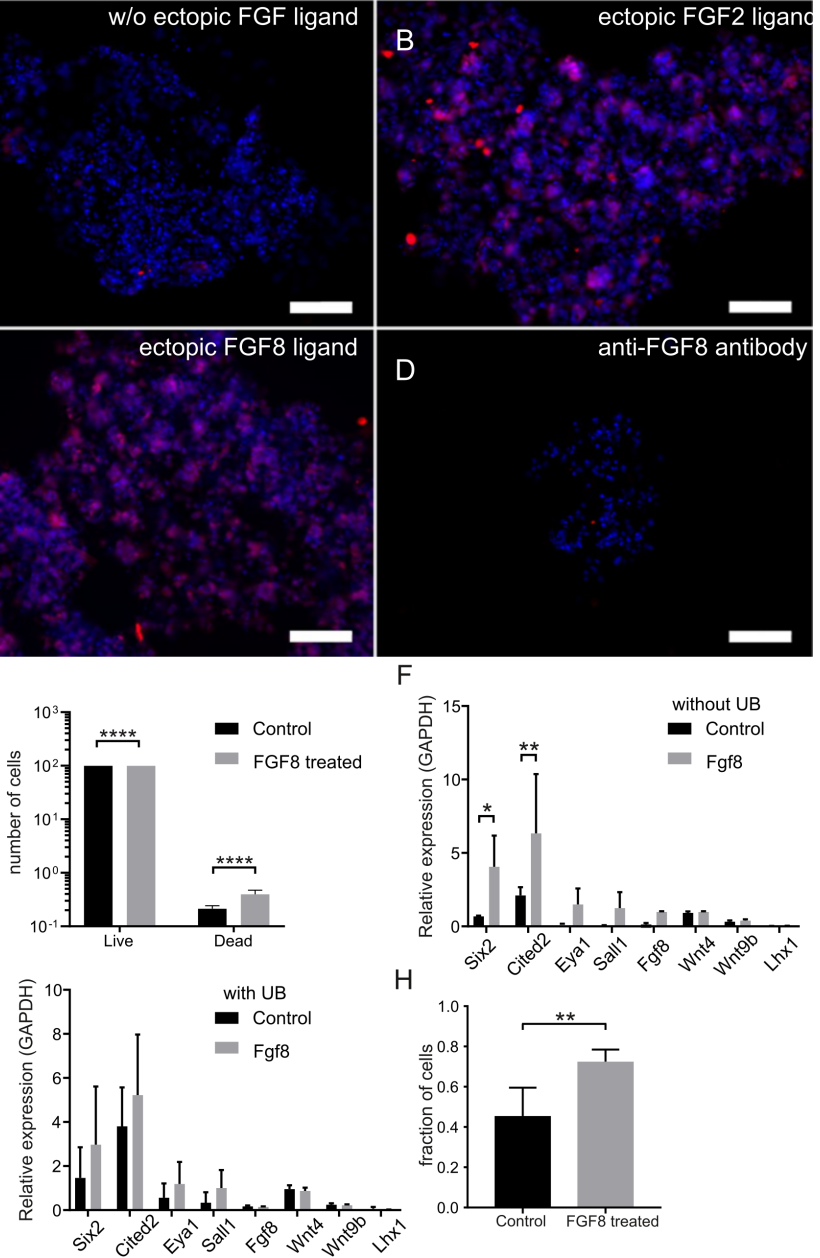

D

$\mathrm{F}$
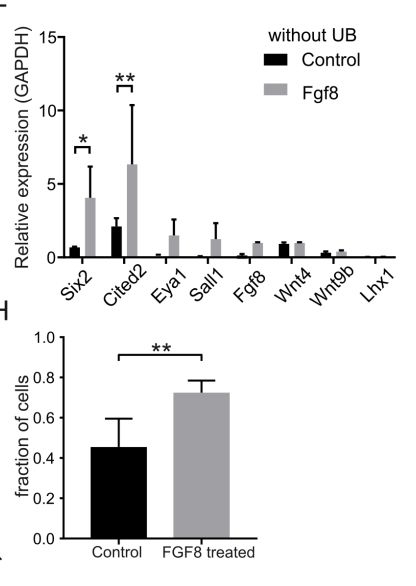

Figure 3: Gene expression analysis in NPCs in the presence or absence of FGF ligand. (A-D) Antibody staining of SIX2 expression with DAPI counterstaining. (A) NPCs lose the expression of SIX2 when the ectopic FGF ligand is not provided. (B,C) NPCs aggregate and retain SIX2 expression in the presence of FGF2 (B) or FGF8 (C). (D) Loss of SIX2 expression and cell death in the presence of anti-FGF8 antibody. (A-D )Scale bar represents $100 \mu \mathrm{m}$. (E) Loss of SIX2 expression and cell death in NPCs treated with anti-FGF8b antibody analysed by flow cytometry. Live/dead analysis was performed using flow cytometry (7-AAD staining), statistics $(\mathrm{n}=3)$ were performed based on two-way ANOVA with significance level $* * * * \mathrm{p}<0.0001$. (F,G) qPCR of tNPC gene expression in FGF8-treated nephrospheres $(\mathrm{F})$ and in the presence of the UB $(\mathrm{G})$. Statistics $(\mathrm{n}=3)$ were performed based on t-test, where ${ }^{*} \mathrm{p}<0.01$ and ${ }^{* *} \mathrm{p}<0.001$; if not specified, the test results were not significant. (H) Percentage of $S I X 2^{+}$cells in response to ectopic Fgf8. Quantitative flow cytometry of dissociated E11.5 kidneys. Samples were collected using FACSCalibur and analyzed using FlowJo, statistics $(\mathrm{n}=10)$ were performed based on t-test, ${ }^{* *} \mathrm{p}<0.001$.

\section{attachment $[12,15,46,47]$.}

To analyze the interplay of chemical signaling and cell motility during mesenchymal condensation, we asked whether a model consisting of i) FGF8-induced mesenchymal cell motility, ii) WNT11-based chemoattraction and iii) SHH-induced repression of FGF8 close to the UB can explain mesenchymal condensation around the UB (Figure 5A). In the computational model, NPCs are initially randomly positioned in a niche bordering a flat patch of the ureteric epithelium (Figure 5E). The NPCs are assigned velocities that depend on the local FGF8 concen-

tration, while the direction of movement is chosen randomly (Figure 5A,B). Epithelial cells are secreting weak concentrations of both WNT11 and SHH, while scenarios of different levels of Fgf8 expression by MM cells are explored (Figure 5F,G Supplementary Figure 3). Mechanically, all cells can adhere to each other when being closer than a threshold distance and detach when moving apart. Simulating this model results in an effective motility gradient with a trap-like region close to the epithelium (Figure 5C,D,F; Supplementary Figure 3). At weak concentrations of FGF8, WNT11 and SHH, only the MM cells closest to the ureteric epithelium show strong displacement towards the ureteric epithelium, but most cells that are further away remain within a few cell diameters of their initial positions (Figure 5C,F; Supplementary Movie 3). At intermediate (2x increased) concentrations of FGF8, significantly more cells aggregate close to the basal surface of the ureteric epithelium (Figure 5C,D,G). At higher FGF8 concentrations (3x increased), cells aggregate everywhere in the niche, which is in line with our bead experiments (Figure 5C, Supplementary Movie 3; Supplementary Movie 2). Lastly, we also observe FGF8 peaks at locations where cells aggregate, resulting in swarm-like motility.

\section{Deletion of $F g f 8$ in late nephrons leads to hypomorph kidney phenotype}

Deletion of Fgf8 before gastrulation is lethal as cells lose the ability to migrate away from the primitive streak [25, 48]. Deletion of Fgfs in the MM using Pax $3^{C r e}$ mice leads to the same phenotype, and newborn mice die shortly after birth [26]. We wondered whether FGF8 also plays a role in later stages of kidney development. In situ hybridisation of Fgf8 revealed its expression in upper cells forming PTAs and this expression was still maintained in the top cells of renal vesicles that form the future comma and S-shape bodies in WT kidneys (Figure 6A-E) To investigate its effect during early nephron formation at PTA stage, we used later expression tissue-specific Cre mouse lines (described in Material and Methods section ). Cre was under the promoter of Wnt4 or Pax8 genes. By utilizing this strategy, we generated mutant $F g f 8^{n / c}$ progeny with $50 \%$ frequency, while $F g f 8^{n /+}$ mice were used as littermate controls. First, to be sure that Fgf8 did not have any function in the UB, we first deleted Fgf8 from the UB using $\mathrm{HoxB} 7^{\mathrm{Cre}}$ mice, and as expected the mutant had no phenotype and the kidneys were similar to those of the wild type mice (Supplementary Figure 4C, Supplementary Figure 5A-D [49]).

Second, we deleted Fgf8 from MM cells by employing two tissue-specific Cre recombinase mice (under the promoter of Pax8 and Wnt4 gene). Pax $8^{C r e}$ is expressed in both the MM and the UB tip (GUDMAP; Supplementary Figure 4A) [50, 51], and $W n t 4^{C r e}$ is only expressed in the MM (Supplementary Figure $4 \mathrm{~B}[52])$. We found that the Fgf8 deletion from the MM using either $\mathrm{Pax} 8^{\mathrm{Cre}}$ or $\mathrm{Wnt} 4^{\mathrm{Cre}}$ led to smaller kidneys as compared to littermate controls (Figure 7A-C). On closer inspection, we found that in both cases kidneys had fewer mature nephrons as compared to littermate controls. Kidneys of Fgf8; $\left(\mathrm{Pax} 8^{\mathrm{Cre}}\right)$ revealed an arrest in S-shaped-body structures whereas the Fgf8; $\left(W n t 4^{C r e}\right)$ showed comma-shaped body structures (Figure 7D-I, higher magnification). Because the complete loss of FGF8 function during kidney development results in a failure of nephron formation around the S-shaped body stage $[25,26]$, these results raised the question is there still some Fgf8 expressed in the $F g f 8^{n / c} ; P a x 8^{C r e}$ and $F g f 8^{n / c} ; W n t 4^{C r e}$ kidneys? Therefore, we analyzed the $\mathrm{Fgf8}$ expression in $\mathrm{Fg} f 8^{n / c} ; \mathrm{Pax} 8^{\mathrm{Cre}}$ kidneys. Functional Fgf8 RNA is expressed at lower level than control litter analysed by qPCR suggesting that the remaining Fgf8 expression cause an hypomorph kidney phenotype. We observed around $40 \%$ of Fgf8 expression at E12.5 in kidneys lacking Fgf8 
bioRxiv preprint doi: https://doi.org/10.1101/2022.02.07.478973; this version posted February 7, 2022. The copyright holder for this preprint (which was not certified by peer review) is the author/funder, who has granted bioRxiv a license to display the preprint in perpetuity. It is made available under aCC-BY-NC-ND 4.0 International license.

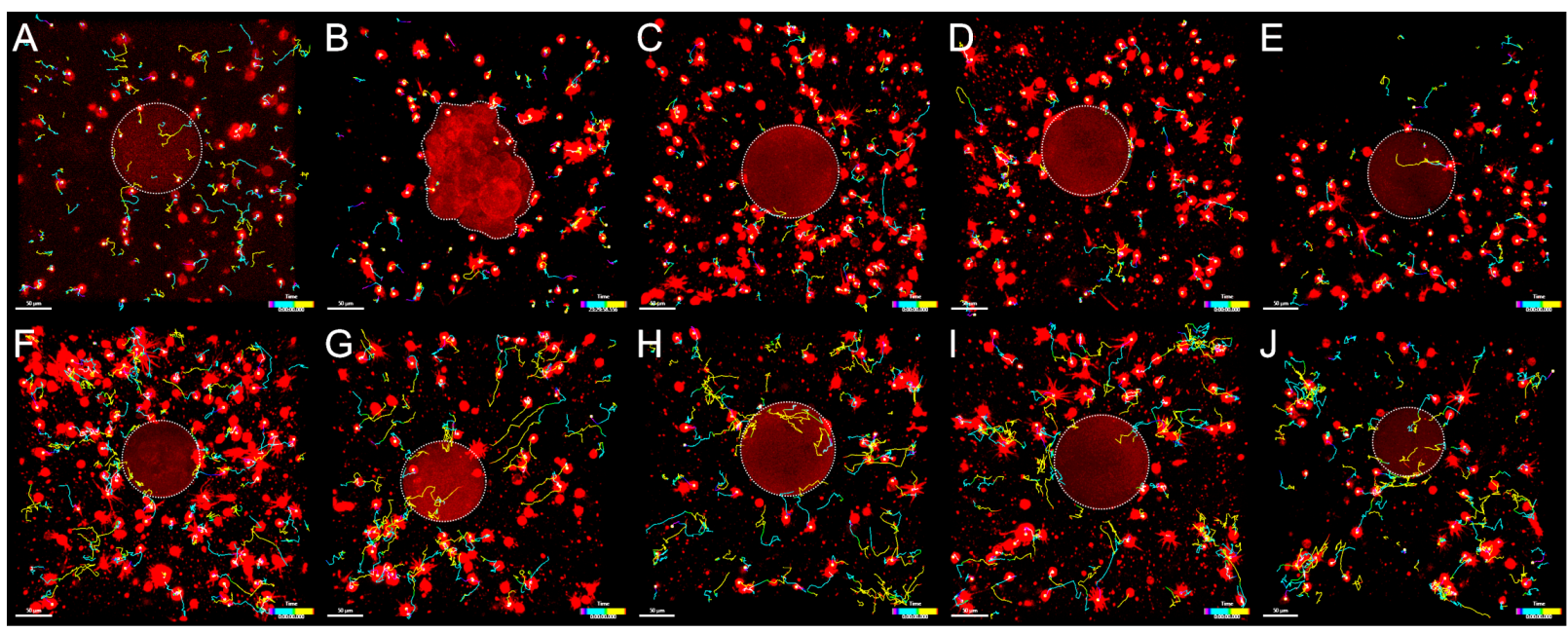

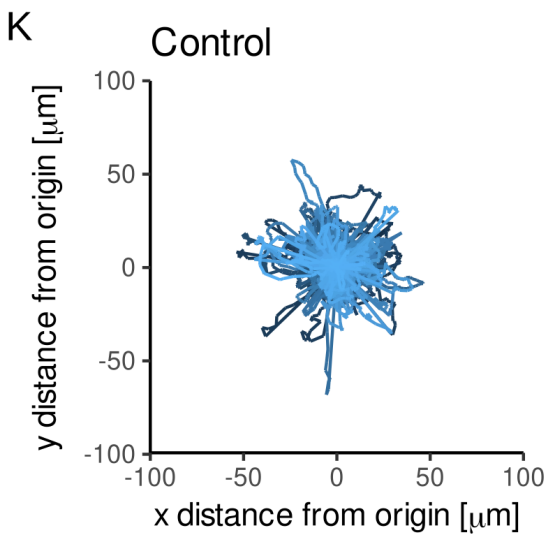

N

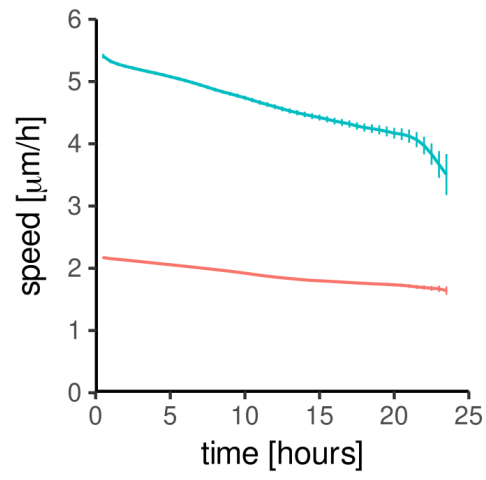

L

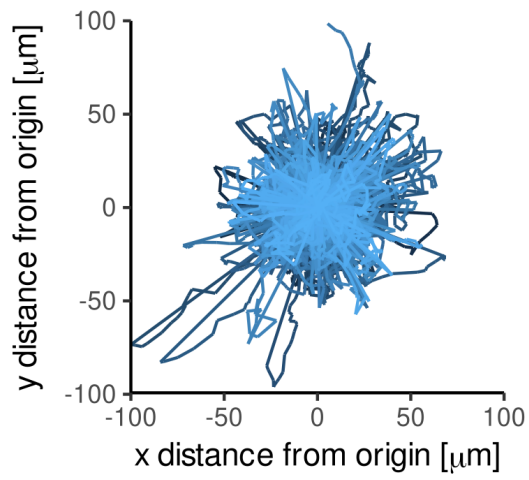

$\mathrm{O}$

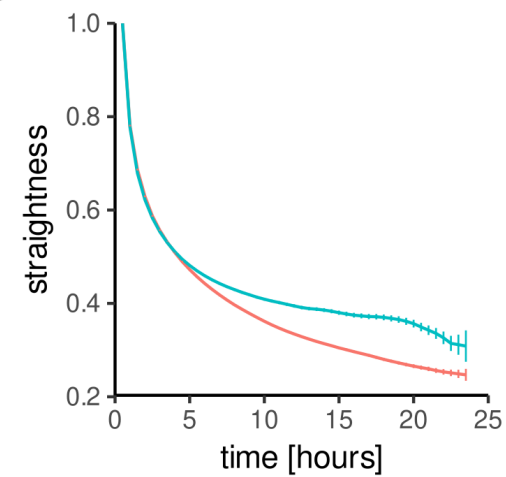

M

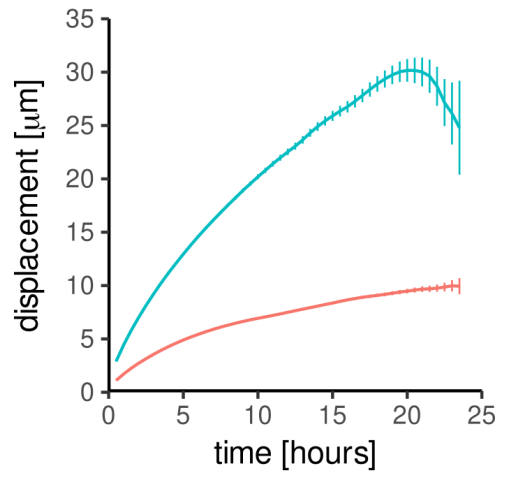

$\mathrm{P}$

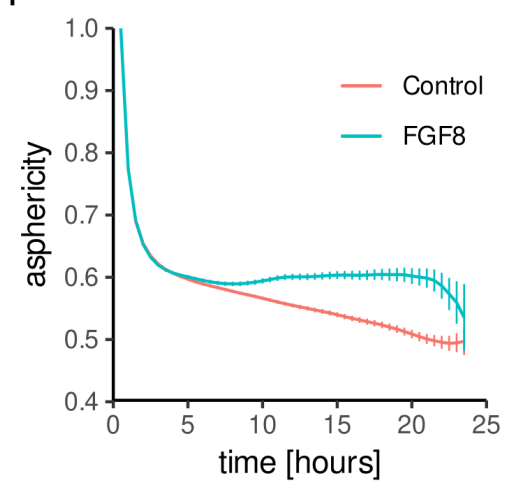

Figure 4: Elevated and undirected NPC motility in response to FGF8. In vitro experiments with control beads (A-E) vs. FGF8 soaked beads (F-J), in a culture of E11.5 MM cells, 5 samples each. Full cell tracks are shown after 24-hour time lapse (FGF8: 534 tracks in toto, control: 538 tracks in toto). Cells were tracked for 24 hrs. Beads are highlighted by dotted white lines. Scale bar represents $50 \mathrm{\mu m}$. Tracks from all samples of each of the two cohorts were pooled (FGF8: 534 tracks, control: 538 tracks). Star plots of control (K) and (L) FGF8 experiments were normalized such that the start point of each track was at the origin. (M,N) Average displacement (Euclidean distance between track start and endpoints) and average speed over time. (O,P) Track straightness: Displacement divided by contour length. Asphericity: The less spherically the steps of a track are distributed, the straighter the track (cf. K,L and [36]). 
bioRxiv preprint doi: https://doi.org/10.1101/2022.02.07.478973; this version posted February 7, 2022. The copyright holder for this preprint (which was not certified by peer review) is the author/funder, who has granted bioRxiv a license to display the preprint in perpetuity. It is made available under aCC-BY-NC-ND 4.0 International license.

A

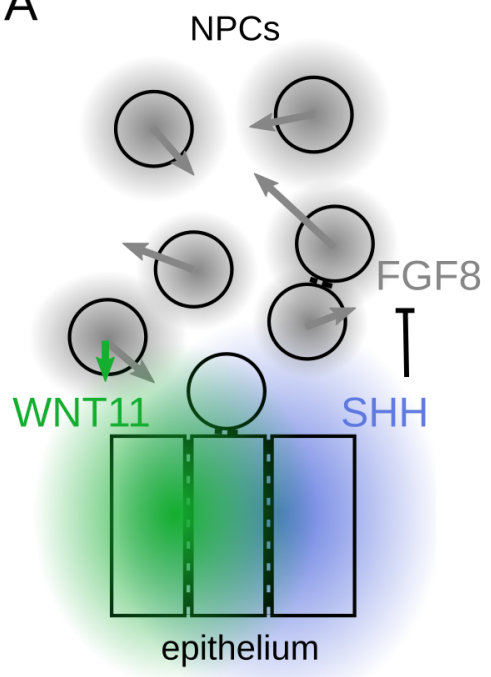

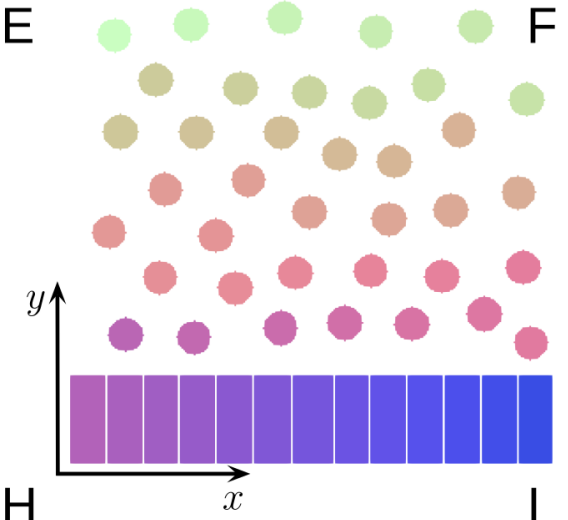

$\mathrm{H}$

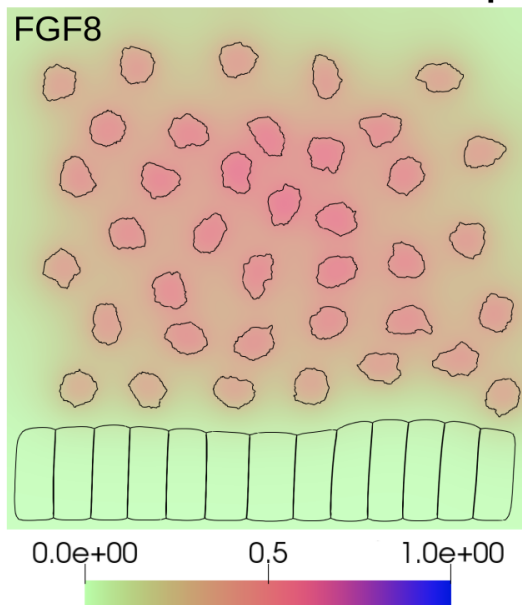

B
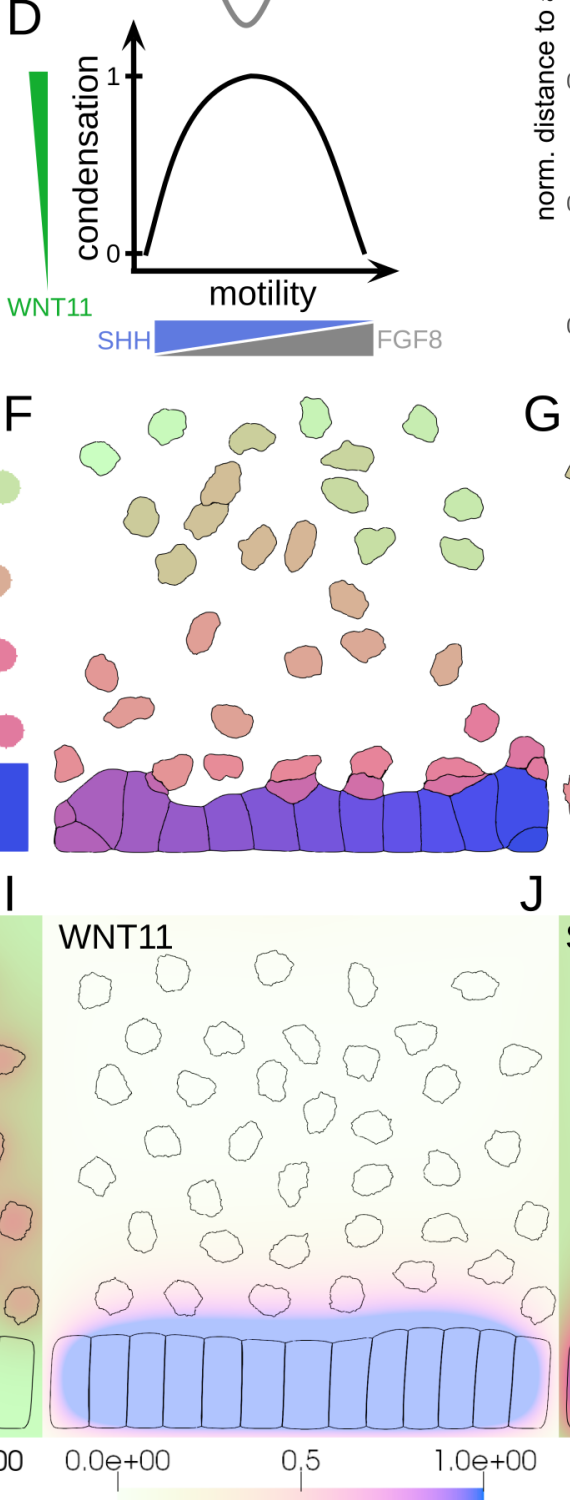

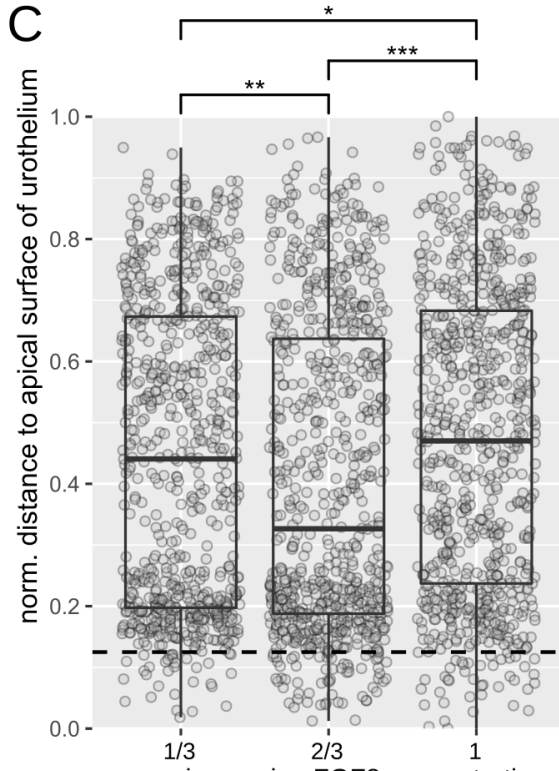

norm. increasing FGF8 concentration

G
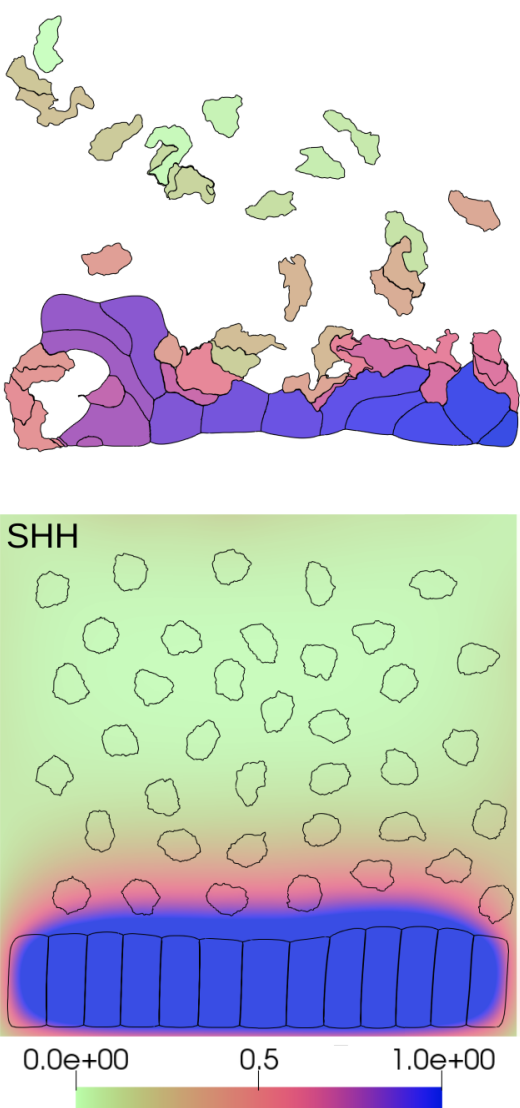

Figure 5: 2D simulations of NPC condensation to the ureteric epithelium. (A) Cartoon of the simulation setup. NPCs express FGF8, can adhere to each other and the ureteric epithelium and move with random velocities whose magnitude depends on FGF8 concentration. Ureteric epithelial cells also adhere to each other and secrete SHH that represses Fgf8 expression, and WNT11, which induces a weak attraction towards the ureteric epithelium (with one order of magnitude lower NPC speeds than with FGF8). NPCs close to the ureteric epithelium are immobilized due to SHH-induced repression of Fgf8. (B) Implementation of random cell motility. The components of the 2-dimensional velocity vector for each cell GeometryNode are picked from normal distributions. This implementation better reflects the amoeboid shape-shifting behaviour of the NPCs. Inlet: Example cell with velocities for a few GeometryNodes. In the simulations, each cell possesses several hundred GeometryNodes. Cf. methods section. (C) Distance of NPCs to ureteric epithelium for simulations with an increasing FGF8 concentration. Only intermediate levels of FGF8 lead to more NPCs being trapped in the region close to the basal surface of the ureteric epithelium (dashed line). Data were pooled from $\mathrm{n}=20$ simulations for each group. Significance levels: ${ }^{*} \mathrm{p}<0.1,{ }^{* *} \mathrm{p}<0.01,{ }^{* * *} \mathrm{p}<0.001$. (D) Motility decreases with an increasing concentration of SHH and increases with increasing concentrations of FGF8 and WNT11. Cells quickly condensate with increasing FGF8 concentrations. In the simulations, the WNT11 concentrations are one order of magnitude smaller than the FGF8 concentrations and accordingly, cell speeds (Table 4,Supplementary Figure 3). (E) Start configuration with dispersed NPCs over a flat patch of the ureteric epithelium. Colours correspond to cell identity. (F) Example of a final configuration with low average FGF8 concentration and limited NPC displacement. (G) Example of a final configuration with an intermediate FGF8 concentration, with increased NPC displacement and mixing. (H-J) Examples of initial concentration gradients of FGF8, WNT11 and SHH. Colour codes represent normalized concentrations. 


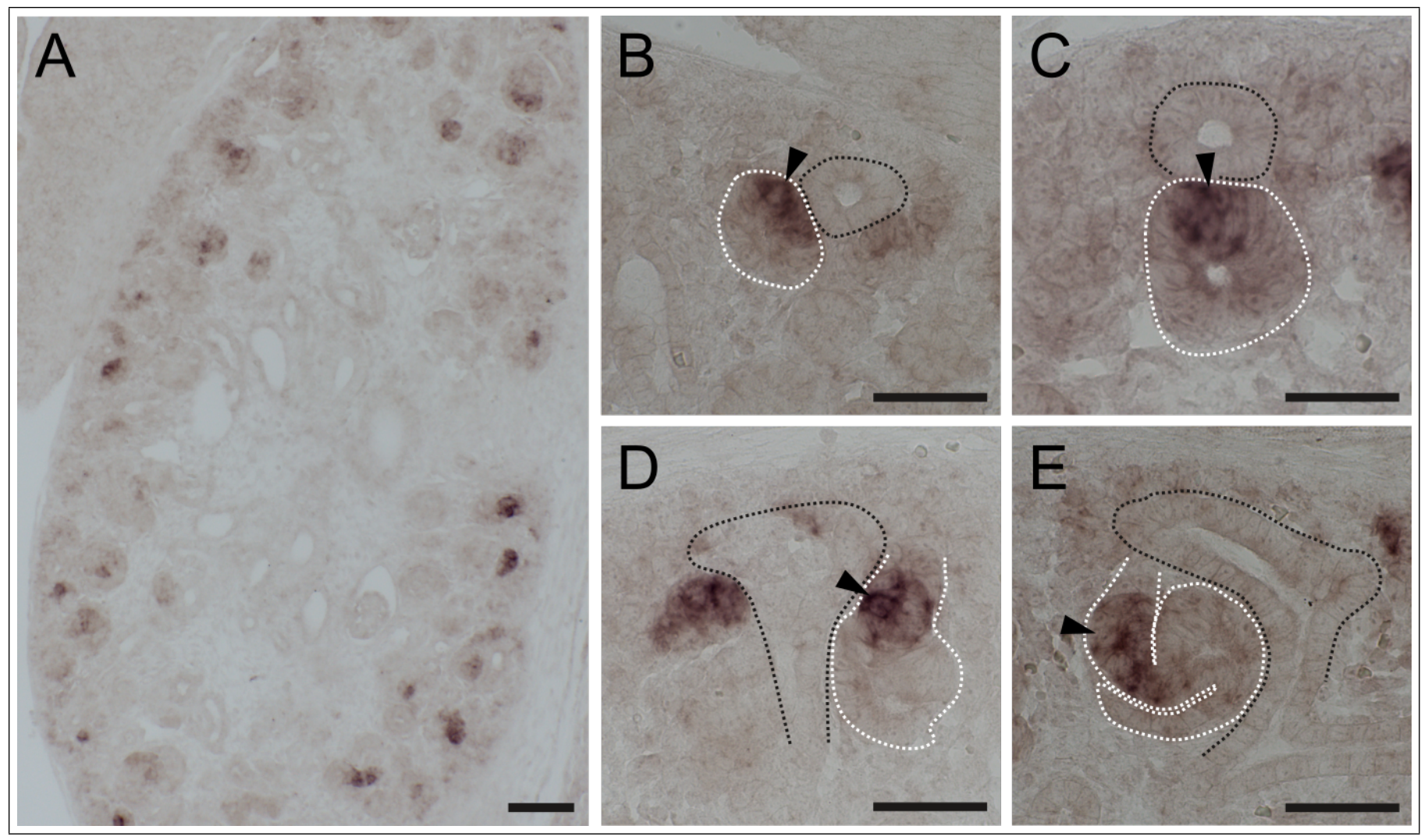

Figure 6: In situ hybridization of Fgf8 in E15.5 embryonic mouse kidney. Taking a closer look at MM derivatives (B-E), the expression of Fgf8 is localized closer to the UB tip. (A) 10x magnification of E15.5 kidney. (B-E) 43x magnified selections. Dotted black lines indicate the ureteric epithelium, dotted white lines indicate (B) pretubular aggregate, (C) renal vesicle, (D) Comma-shaped body and (E) S-shaped body. Black arrows indicate cells expressing Fgf8. Scale bar for (A) 100 um and (B-E) $50 \mu \mathrm{m}$.

(Figure 7J). These data demonstrate that FGF8 is required within the developing kidney to support the further development of the nephrons, and the reduced Fgf8 expression during nephrogenesis induces hypomorph phenotypes.

\section{Late deletion of Fgf8 leads to incorrect localization patterns of NPCs in the nephrogenic niche}

tNPCs in the tip region of the UB are marked by Six2 expression along with Cited1/2 and Eya1 (Figure 1) [2, 23, 53, 54]. Wnt9b that is expressed and secreted by the UB regulates the transition from tNPCs to cNPCs (Figure 1) [12]. This transition is marked by a decrease of Cited $1 / 2$ expression $[2,14,23]$. At the same time, the expression of Wnt4 in an aggregated subset of cNPCs that are located at the tip-trunk interface of the UB indicates the onset of nephron formation (Figure 1) $[11,18]$. When we compared the expression of Six2 in wild type kidneys to tissuespecific deletions of $\mathrm{Fgf8}$ in $\mathrm{Fgf8} 8^{n / c} ; \mathrm{Pax} 8^{\mathrm{Cre}}$ (MM and UB tip) or $F g f 8^{n / c} ; W n t 4^{C r e}$ (only MM) kidneys, we found untypical $S i x 2^{+}$expression patterns, indicating disorganized NPCs (Figure 8A-C). Deletion of Fgf8 in $F g f 8^{n / c} ; \operatorname{Pax} 8^{C r e}$ kidneys did not seem to alter the expression of $W n t 9 b$ as compared to the littermate controls (Figure 8D-F) and as expected Wnt9b was not affected in $F g f 8^{n / c} ; W n t 4^{C r e}$ kidneys. On the other hand, the expression of Wnt4 was decreased in both $\mathrm{Fg} \mathrm{f8} 8^{n / c} ; \mathrm{Pax} 8^{\mathrm{Cre}}$ and $F g f 8^{n / c} ; W n t 4^{C r e}$ kidneys (Figure 8H,I) as compared to the littermate controls (Figure 8G). Further, in both $F g f 8^{n / c}$; $\mathrm{Pax} 8^{\mathrm{Cre}}$ and $\mathrm{Fg} f 8^{n / c} ; W n t 4^{C r e}$ kidneys, condensation of NPCs expressing Eya1 and Cited1 around the UB was perturbed, while the expression of Cited1 was still maintained (Figure 8K-L,N-O). Together, these data show an incorrect localization pattern of
NPCs in kidneys where Fgf8 is deleted via either $\operatorname{Pax} 8^{\mathrm{Cre}}$ or Wnt $4^{\text {Cre }}$ mouse lines.

\section{Without the expression of $F g f 8$ after kidney induction, NPCs still accumulate at the tip of the UB}

To further confirm the obtained results of our in vitro experiments (cultured of $\mathrm{Fgf}^{n / c} ; \mathrm{T}^{\mathrm{Cre}}$ kidneys and the effect of FGF8 onto MM cells in the bead culture experiment), we stained NPCs and UB cells with fluorescent markers on these two mouse lines, that deletes Fgf8 later in nephrogenesis after E11.5. To analyse the complete PTAs formation, we have selected E16.5 stage where most of the tubules are already formed. Staining of $\mathrm{Six}^{+}$NPCs in E16.5 kidneys obtained from crossing $F g f 8^{n / c} ; \mathrm{Pax} 8^{C r e}$ revealed a thicker cap mesenchyme at the tips of UBs, suggesting differences in niche composition as compared to littermate controls (Figure 9A-B). A thicker layer of $S I X 2^{+}$ cells in the tip region of the UB indicates that NPCs either failed to fully condensate around the UB or that they were not primed as cNPCs (Figure 9C). Similar results were obtained when Fgf8 was deleted using $W n t 4^{C r e}$ (Figure 9D-E). With $W n t 4^{C r e}$ mediated deletion of $F g f 8$, the $S I X 2^{+}$population failed to condensate around the UB tip as it can be observed in $\mathrm{Pax} 8^{\mathrm{Cre}}$ mediated deletion of Fgf8 (Figure 9F). These results confirm the observations from the in situ hybridisation experiments (Figure 8) suggesting that the NPCs, the SIX2 ${ }^{+}$ cells, accumulate around the UB tip and that NPC induction is interrupted failing the PTAs formation. 

perpetuity. It is made available under aCC-BY-NC-ND 4.0 International license.

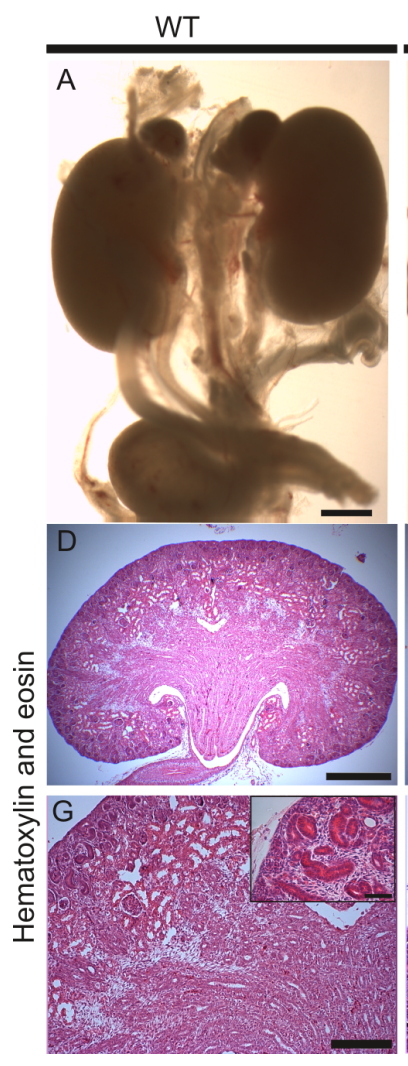

Pax $8^{\mathrm{Cre}} ; \mathrm{Fgfr}^{\mathrm{n} / \mathrm{c}}$

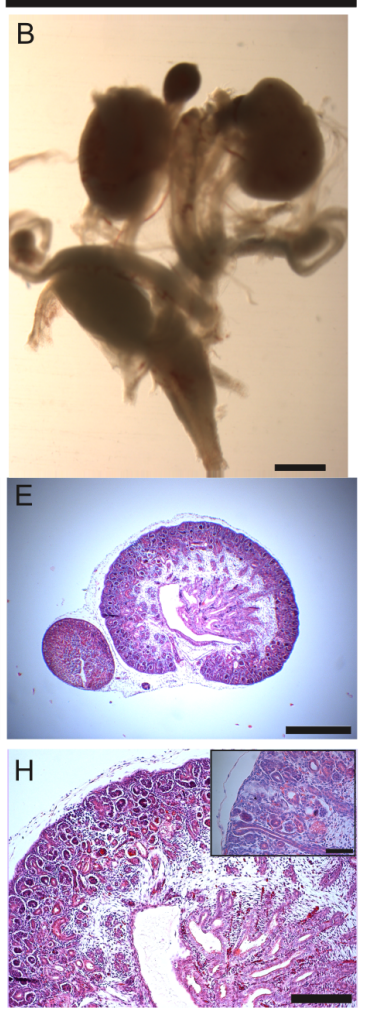

Wnt4 ${ }^{\mathrm{Cre}} ; \mathrm{Fgfr}^{\mathrm{n} / \mathrm{c}}$

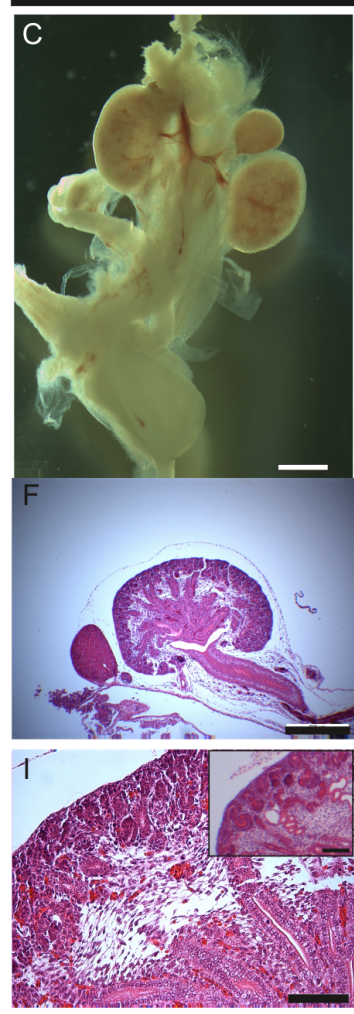

Fgf8 E12.5

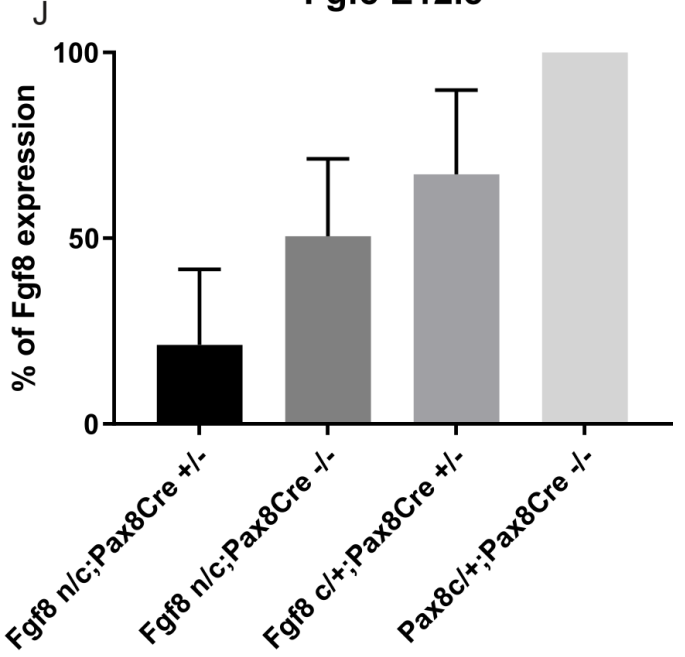

Figure 7: Fgf8 deletion in E16.5 hypomorph mouse embryos. (A-C) the deletion of Fgf8 from the metanephric mesenchyme led to smaller kidneys as compared to littermate controls. (A) Urogenital system of littermate controls, (B) Cre-mediated deletion of Fgf8 using Pax $8^{C r e}$ and (C) Wnt4 ${ }^{C r e}$. (E,F,H,I) Hematoxylin-Eosin staining shows smaller kidneys lacking mature nephrons. (J) qPCR of Fgf8 in E12.5 kidneys of Fgf8 Pax $8^{C r e}$. The inserts are higher magnification selections. Scale bars for (A-F) are $500 \mu \mathrm{m}$ and (G-I) are $100 \mu \mathrm{m}$.

\section{Discussion}

Intercellular signaling between NPCs and UB cells is key for mammalian kidney development, and it is known to be tightly controlled. Failure of the expression of key genes such as Six2, Fgf8, Wnt4, Wnt $9 b$ and others leads to developmental defects or even to embryonic lethality $[2,3,18,25,26]$. FGF8 is also known to be involved in the activation of the kidney-specific genes Wnt4 and $\operatorname{Lim} 1(\operatorname{Lh} x 1)$ [25, 27].

In this work, we have used several cre-based mouse lines to establish that Fgf8 expression is located in the MM and imparts its function on the nephron progenitor cells. Deletion of Fgf8 from the MM resulted in embryonic kidneys that lacked mature nephrons, which led to smaller hypomorphic kidneys and postnatal death. As Fgf8-deficient kidneys lack Wnt4 expression, Fgf8 is required for Wnt4 expression [25, 26]. While it is known that WNT4 initiate MET [18], in accordance with previously published results, we also observed that independently of WNT4, FGF8 is required for the condensation of NPCs [25]. We found that in kidneys where FGF8 signaling was blocked using an antiFGF8 antibody, NPCs did not condensate to form pretubular aggregates. But upon removal of the antagonising agent, PTA formation was recovered. This indicates that even though FGF8 is upstream of WNT4, it regulates NPC condensation, which is itself required for PTA formation before WNT4-induced MET of PTAs.

FGFs are also involved in the maintenance of NPCs during early nephrogenesis [31]. Though previously only a modest effect of FGF8 on cap marker transcription has been observed in $2 \mathrm{D}$ cultures [31], our results with $3 \mathrm{D}$ cultures show that without FGF8, Six2 expression is lost, but when adding ectopic FGF8 and in the presence of the UB, the expression of Six2 is maintained as compared to the vehicular control. Similarly, the expression of other tNPC markers such as Cited1/2 and Eya1 is also maintained in the presence of FGF8. We explain the discrepancy with the previous observations through improved culture conditions, as it has been shown that culturing NPCs in a $3 \mathrm{D}$ micro-environment leads to an improvement in nephrogenic potential [55]. In conclusion, FGF8 seems to be required for the expression of tNPC markers and thus tNPC maintenance, though it might not determine NPC fate, as cNPCs that form PTAs also express FGF8.

To understand how FGF8-induced NPC motility could lead to NPC condensation, we employed a computational model that simulates the combined effect of FGF8-induced motility, SHHbased repression of Fgf8 and weak chemoattraction by WNT11. Our simulations showed that, on the one hand, graded motility perpendicular to the UB surface due to the repression of Fgf8 by SHH and, on the other hand, the weak attraction of NPCs by UB-secreted WNT11 together established a trap-like region near the UB that captured passing NPCs. Importantly, with FGF8induced NPC motility significantly more NPCs were trapped than with low motility and weak attraction. We, therefore, propose that FGF8-induced chemokinesis of NPCs, together with signals from the UB, represent a robust mechanism of NPC condensation in the nephrogenic niche. Our proposed mechanism may be involved both in the initial formation of the cap mesenchyme and the formation of pretubular aggregates at the tip-trunk interface of the UB. A better understanding of both processes requires an investigation of the spatiotemporal gradients of the involved factors during early nephrogenesis.

In conclusion, our results indicate that FGF8 is a chemokinetic agent that is expressed in the metanephric mesenchyme and 
bioRxiv preprint doi: https://doi.org/10.1101/2022.02.07.478973; this version posted February 7, 2022. The copyright holder for this preprint (which was not certified by peer review) is the author/funder, who has granted bioRxiv a license to display the preprint in perpetuity. It is made available under aCC-BY-NC-ND 4.0 International license.
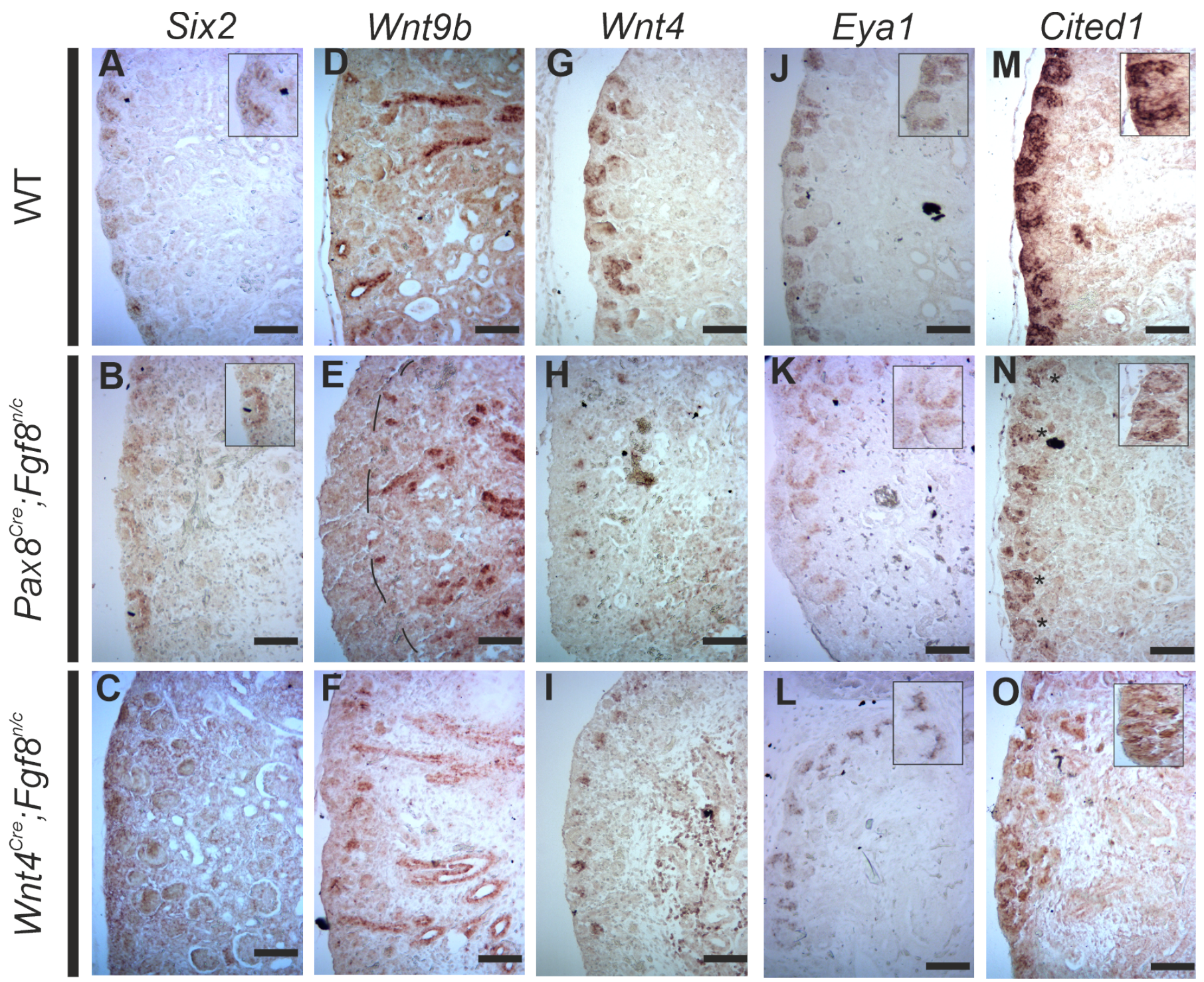

Figure 8: Gene expression in littermate control and hypomorph mutant kidneys.(A-C) Expression of SIX2 was observed around UB tips on the kidney cortex, but in mutant kidneys under Pax8 or Wnt4 Cre its expression was disorganized. (D-F) Expression of $W n t 9 b$ was restricted to the UB in littermate controls, $P a x 8^{C r e}$ and $W n t 4^{C r e}$ mediated Fgf8 deletion. (G-I) Wnt4 expression was observed in littermate controls and mutants, but the expression was reduced in the mutants kidneys. (K-L and N-O) Expression of Eya1 and Cited1 was also disorganised in mutants kidneys as compared to littermate controls. Higher magnification of the staining to visualise the disorganisation of the expressing cells. Inset shows higher magnification image of the in situ. Scale bar represents $100 \mu \mathrm{m}$.

is required for the condensation of NPCs while being involved in tNPC maintenance. Further work is required to reveal how FGF8 along with its receptors and inhibiting factors orchestrates NPC condensation, its involvement in PTA formation, and its influence on cell fates to form the various structures of the nephron.

\section{Methods}

\section{Mouse strains and tissue collection}

In this work, the mouse experiments were conducted in accordance with the Finnish and EU legislation. The Finnish National Animal Experiment Board approved all animal experiments and experiments were conducted under internal licenses issued by the Laboratory Animal Centre of the University of Oulu, Finland. To delete $F g f 8$ from mouse kidneys we crossed $F g f 8^{\Delta 2,3 /+}$ males with $\operatorname{Pax} 8^{\mathrm{Cre} /+}$ female. The progeny was genotyped and females with $\operatorname{Pax} 8^{\mathrm{Cre} /+} ; \mathrm{Fg} f 8^{n /+}$ genotype were crossed with
Fgf $8^{\text {Floxed/Floxed }}$ male. The progeny were genotyped and embryos with genotype $F g f 8^{n / c} ; P a x 8^{C r e /+}$ were selected for the experiments. Similar strategy was utilized for $W n t 4^{e G F P C r e /+}$ and $\mathrm{HoxB} 7^{\mathrm{Cre} /+}$. To delete Fgf8 using $T^{C r e}$, a similar strategy was employed as in Perantoni et al. [25]. Briefly, females with genotype $F g f 8^{\text {Floxed/Floxed }}$ were crossed with males with genotype $T^{C r e / C r e} ; F_{f f} 8^{\Delta 2,3 /+}$ and progeny with genotype of $T^{C r e /+} ; F g f 8^{n / c}$ was used for this study. Expression of Cre and deletion of Fgf8 were assessed by genomic PCR as described in respective articles. Timed matings were checked at noon for vaginal plug and upon identification was considered to be E0.5. To obtain kidney samples, pregnant females were euthanized with $\mathrm{CO}_{2}$ followed by cervical dislocation, as per the institutional guidelines. Embryos were collected in sterile PBS and kidneys were dissected in $1 \mathrm{X}$ PBS with calcium and magnesium. Dissected kidneys were further treated depending on the experiment. 
bioRxiv preprint doi: https://doi.org/10.1101/2022.02.07.478973; this version posted February 7, 2022. The copyright holder for this preprint (which was not certified by peer review) is the author/funder, who has granted bioRxiv a license to display the preprint in perpetuity. It is made available under aCC-BY-NC-ND 4.0 International license.
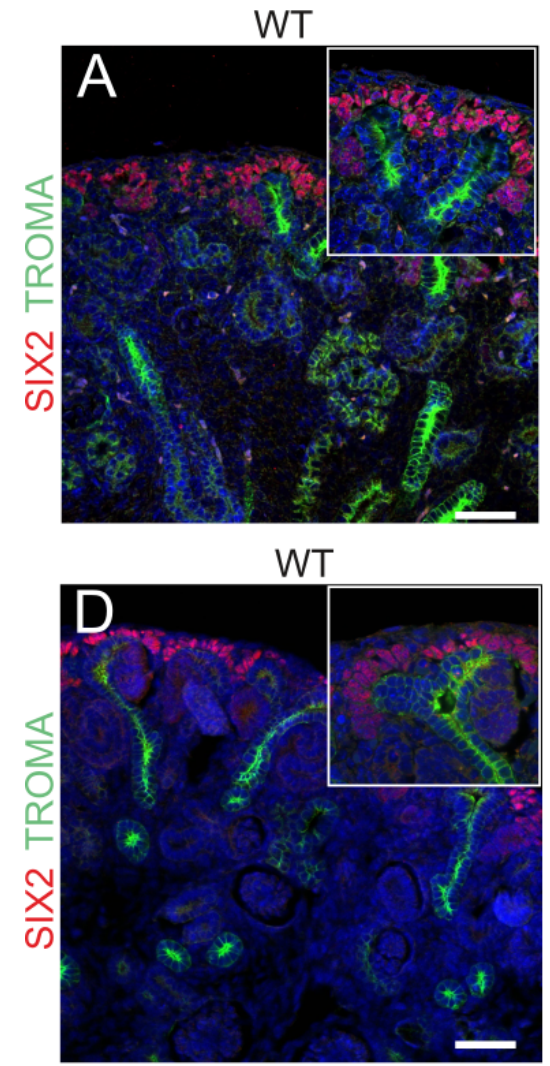

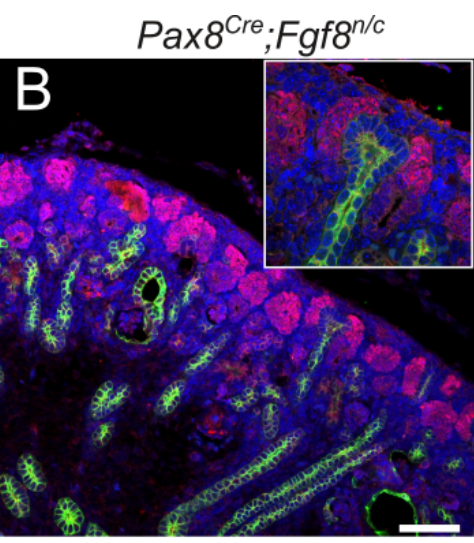

Wnt4 ${ }^{\mathrm{Cre}} ; \mathrm{Fgf8}^{\mathrm{n} / \mathrm{c}}$

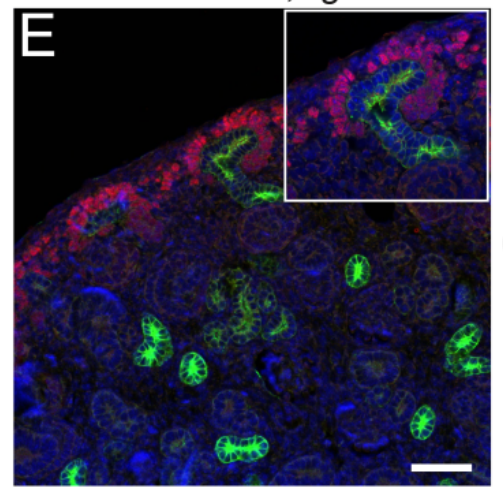

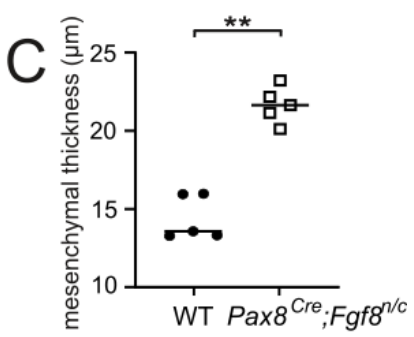
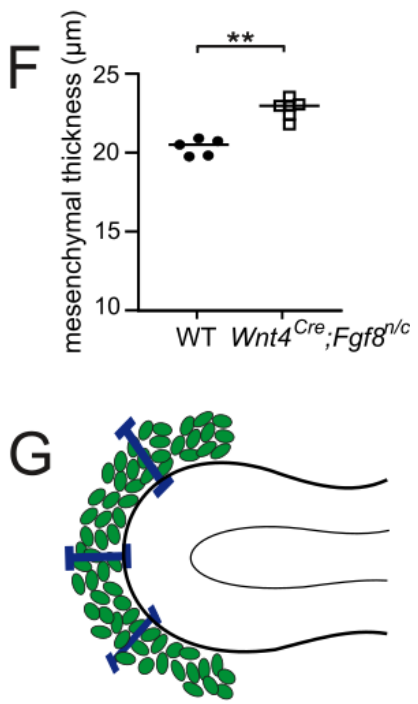

Figure 9: Accumulation of NPCs in the tip region in hypomorph kidneys. (A-C) When Fgf8 was deleted using Pax $8^{C r e}$ (B) or $W n t 4^{C r e}(\mathrm{E})$, NPCs did not form a condensed cap mesenchyme, but they rather accumulated at the tip region of the UB as compared to the littermate controls (A,D), respectively. The inserts are higher magnification selections. (C) Distance of the last layer of the NPCs from the UB tip of E16.5 Fgf $8^{n / c} ; \mathrm{Pax}^{\mathrm{Cre}}$ kidneys. (F) Distance of the last layer of the NPCs from UB tip of E16.5 $\mathrm{Fgf}^{n / c} ; \mathrm{Wnt} 4^{\mathrm{Cre}}$ kidneys. (G) Cartoon depicting how the measurements were done for calculating the distance of NPCs around the UB tip. Kidneys were stained with SIX2 (NPCs, red), Troma-1 (UB, green) and DNA was counter stained with Hoechst33342 (Blue). Statistics were performed in the kidneys $(\mathrm{n}=6)$ per sample, $p$ values were calculated using $t$-test, ${ }^{* *} \mathrm{p}<0.01$. Scale bar represents $100 \mu \mathrm{m}$.

\section{Histology and immunofluorescence}

\section{Hematoxylin-Eosin staining}

For light microscopy, paraffin-embedded kidney sections were stained with hematoxylin-eosin, following standard procedures according to Veikkolainen et al. [60].

\section{Immunostaining}

Embryonic kidneys were collected and dissected at E11.5, E12.5, E16.5 and P0 from genotyped mutant and littermate controls. Samples were fixed in $4 \%$ paraformaldehyde (PFA) overnight at $4^{\circ} \mathrm{C}$ and dehydrated in serial dilutions with $25 \%$ ethanol $\rightarrow$ $50 \%$ ethanol $\rightarrow 75 \%$ ethanol $\rightarrow 100 \%$ ethanol in water with an incubating time in each step for $45 \mathrm{mins}$ or until the sample sinks to the bottom of the test tube. At this point, the samples were transferred in a clearing solution (xylene), twice, for 60 mins each. Samples were moved to melted paraffin, thrice, for $60 \mathrm{mins}$ each, and then these samples were carefully embedded in paraffin blocks and stored at $4^{\circ} \mathrm{C}$. Embedded samples were sectioned $(14 \mu \mathrm{m})$ with Lecia microtome, and slides were prepared with up to 4 samples on each slide. To perform staining, sections were selected, and slides were prepared by heating at $55^{\circ} \mathrm{C}$ to melt paraffin. To deparaffinise, slides were incubated in xylene solution, twice, $5 \mathrm{mins}$ each. To remove xylene, slides were incubated in the $100 \%$ ethanol, twice, $5 \mathrm{mins}$, and then hydrated in $95 \%$ ethanol $\rightarrow 75 \%$ ethanol $\rightarrow 50 \%$ ethanol in water for 5 mins each. Antigen retrieval was performed $1 \mathrm{mM}$
EDTA-NaOH solution ( $\mathrm{pH} 8.0$ ) or $10 \mathrm{mM} \mathrm{Na-citrate-citric} \mathrm{acid}$ solution ( $\mathrm{pH}$ 6.0) in pressure cooker for 10mins [61]. After antigen retrieval samples were incubated, for 60 mins, in blocking solution (1X PBS + 0.01\% Triton-X100 + Serum (Serum was selected based on antibody reactivity)). Primary antibody incubation duration and temperature was. Images were accquired on Olympus BX51WI upright mircroscope with Hamamatsu ORCA-ER digital camera.

\section{Nephrospheres}

Sphere-Forming Assay was performed as per Ihermann-Hella et al. with minor modifications [32]. MM from E11.5 kidneys from CD-1 mice were dissociated with Collagenase Type 3 (Worthington Biochemical Corporation; Cat \#LS004180) and DNase I (New England Biolabs; Cat \#M0303S) in physiological buffer at $37^{\circ} \mathrm{C}$. To obtain a single-cell suspension, after stopping the activity of the enzymes with complete media, the cell suspension was strained through $0.45 \mu \mathrm{m}$ cell strainer. The total obtained cell suspension was divided into four equal parts, from which each part was mixed with two parts of Matrigel (Corning; Cat \#354277) and were allowed to attach for 10 mins at $37^{\circ} \mathrm{C}, 5 \%$ $\mathrm{CO}_{2}$ and $95 \%$ humidity. Media containing Src-kinase inhibitor (10 $\mu M$ PP2; Tocris Bioscience; Cat \#1407) and/or FGF8b (100ng/ml; R\&D Systems; Cat \#423-F8) 24hrs. 
bioRxiv preprint doi: https://doi.org/10.1101/2022.02.07.478973; this version posted February 7, 2022. The copyright holder for this preprint (which was not certified by peer review) is the author/funder, who has granted bioRxiv a license to display the preprint in perpetuity. It is made available under aCC-BY-NC-ND 4.0 International license.

Table 1: Mouse lines used in this work.

\begin{tabular}{|c|c|c|c|}
\hline Reagents type (Species) or resource & Designation & Source or reference & Identifiers \\
\hline Genetic reagent (Mus musculus) & Pax $8^{\mathrm{Cre} /+}$ & [50] & MGI:J:80208 \\
\hline Genetic reagent (Mus musculus) & $W n t 4^{e G F P C r e /+}$ & {$[52]$} & RRID:IMSR_EM:10011 \\
\hline Genetic reagent (Mus musculus) & $\mathrm{Hoxb} 7^{\mathrm{Cre} /+}$ & {$[49]$} & MGI:J:79481 \\
\hline Genetic reagent (Mus musculus) & Fgf $8^{\text {Floxed/Floxed }}$ & {$[56]$} & MG:2150347 \\
\hline Genetic reagent (Mus musculus) & $F g f 8^{\Delta 2,3 /+}$ & {$[56]$} & MGI:2150346 \\
\hline Genetic reagent (Mus musculus) & $T^{C r e /+}$ & {$[25]$} & MGI:J:101175 \\
\hline Genetic reagent (Mus musculus) & $\operatorname{Rosa} 26^{m T / m G}$ & {$[57]$} & MGI:J:124702 \\
\hline Genetic reagent (Mus musculus) & $S i x 2-T G C^{t g}$ & {$[58]$} & MGI:J:148455 \\
\hline Genetic reagent (Mus musculus) & Rosa26 - LacZ $Z^{\operatorname{lox} P}$ & {$[59]$} & MGI:J:64292 \\
\hline
\end{tabular}

Table 2: Antibodies, growth factors, agonists and antagonists.

\begin{tabular}{|c|c|c|}
\hline Product & Final Concentration & Company; Catalogue number; Identifiers \\
\hline Anti-SIX2 & $1: 200$ & $\begin{array}{l}\text { Proteintech Group; Cat\# 11562-1-AP; } \\
\text { RRID:AB_2189084 }\end{array}$ \\
\hline Anti-FGF8b & $1: 200$ & R\&D Systems; Cat\# AF-423-NA; RRID:AB_2262650 \\
\hline Anti-Flag M2 & $1: 300$ & Sigma-Aldrich; Cat\# F1804; RRID:AB_262044 \\
\hline Anti-TROMA1 & $1: 200$ & DSHB; Cat\# Troma1; RRID:AB_531826 \\
\hline Anti- $G S K 3 \beta$ & 1:1000 & Cell Signalling; Cat\#9315S; RRID:AB_490890 \\
\hline Anti-phospho- $G S K 3 \beta$ & 1:1000 & Cell Signalling; Cat\#9336S; RRID:AB_331405 \\
\hline Anti- $\beta-A C T I N$ & $1: 1000$ & Cell Signalling; Cat\#4970S; RRID:AB_2223172 \\
\hline Goat anti-Rabbit & 1:1000 & ThermoFisher Scientific; Cat\# A-11008; \\
\hline AlexaFlour488 & & RRID:AB_143165 \\
\hline Goat anti-Rat & $1: 1000$ & ThermoFisher Scientific; Cat\# A-11081; \\
\hline AlexaFlour546 & & RRID:AB_2534125 \\
\hline Goat anti-Rabbit & $1: 1000$ & AgilentDako; Cat\# P0448; \\
\hline $\mathrm{HRP}$ & & RRID:AB_2617138 \\
\hline rmFGF8b & $100 \mathrm{ng} / \mu L$ & R\&D Systems; Cat\# 423-NA \\
\hline PP2 & $10 \mu \mathrm{M}$ & Tocris Bioscience; Cat\# 1407; PubChem ID: 4878 \\
\hline Bio & $10 \mu \mathrm{M}$ & Torcis Bioscience; Cat\# 3194; PubChem ID: 5287844 \\
\hline Matrigel (BME) & & Corning; Cat\# 354277 \\
\hline
\end{tabular}

\section{Real time qPCR}

To remove nephrospheres from the embedded matrigel, plates were chilled on ice for one hour on a shaking platform. Liquefied matrigel solution was collected and centrifuged at 10621 r.c.f at $4^{\circ} \mathrm{C}$ for $10 \mathrm{~min}$. Pellet was washed twice with DEPC treated $1 \mathrm{XPBS}$ at 2655 r.c.f at $4^{\circ} \mathrm{C}$ for $5 \mathrm{~min}$. Pellet was flash-frozen in liquid nitrogen until required. RNA extraction was performed using RNeasy mini (Qiagen; Cat\# 74104) and cDNA synthesis was performed using First Strand cDNA synthesis kit (Thermo Scientific; Cat\# K1612), where 100ng of RNA was used as a template. cDNA was diluted 1:1 with PCR grade water and for the qPCR reaction $2 \mu L \mathrm{cDNA}, 1.2 \mu \mathrm{L}$ each of forward and reverse primer along with $0.6 \mu L$ of PCR water and $5 \mu L$ Brilliant Sybr Green III qPCR master mix (Agilent Technologies; Cat\# 600882). qPCR was carried out at CFX96 Touch System (BioRad) with a program $95^{\circ} \mathrm{C} 10 \mathrm{mins},\left[95^{\circ} \mathrm{C}\right.$ for $20 \mathrm{sec}, 60^{\circ} \mathrm{C}$ for $20 \mathrm{sec}, 72^{\circ} \mathrm{C}$ for $\left.20 \mathrm{sec}\right]$ for 40 cycles followed by melt curve. qPCR was performed with three biological replicates in three technical replicates.

\section{Western Blotting and Antibody validation}

For the validation of anti-FGF8b antibody, a Flag-tagged FGF8b clone was obtained from Genscript CloneID: OMu22892D (NCBI Nucleotide: NM_001166361.1) and was overexpressed in CHOK1 cells (ATCC: \#CCL-61). The media was collected from FBS starved CHO-K1 cells expressing FGF8b and precipitated using the TCA method as described in Fic et al [62] and western blot was performed with controls (commercially bought rmFGF8b, cell lysate of validated protein-expressing Flag tag and CHO-K1 cell lysate).

For $G S K 3 \beta$ quantification, nephrosphere culture was setup (Material and Mehtods ). The cells were extracted as previously mentioned (Material and Method ). Cells where lysed using 1X RIPA cell lysis solution (Cell Signaling; Cat\#9806) supplemented with cOmplete ${ }^{\mathrm{TM}}$, Mini, EDTA-free Protease Inhibitor Cocktail (Roche; \#04693159001). Protein quantity estimation was performed using Pierce ${ }^{\mathrm{TM}}$ BCA Protein Assay Kit (Pierce; Cat\#23225). 50mg of total protein was loaded on to in-house prepared $12.5 \%$ SDS-PAGE separating gel and 6\% stalking gel and separation was performed for $90 \mathrm{mins}$ at $110 \mathrm{~V}$ at room temperature. Transfer was carried out on to NCP Porablot Membrane (Macherey-Nagel; Cat\#12807411) for 90mins at 90V at $4^{\circ} \mathrm{C}$. The membrane was blocked with $5 \%$ BSA solution and all the primary antibodies were incubated for overnight at $4^{\circ} \mathrm{C}$, while secondary antibodies were incubated for $60 \mathrm{mins}$ at room temperature. The detection was performed using LumiGLO Reagent (Cell Signalling; Cat\#7003S) on Fujifilm LAS-3000 Imager. For sequential protein detection the antibodies were striped away, by incubating the membranes with $0.2 \mathrm{M} \mathrm{NaOH}$ solution for $15 \mathrm{mins}$ at room temperature and re-blocking with BSA. The protein quantitation was performed using ImageQuant TL8.1 (Cytiva LifeSciences). 
bioRxiv preprint doi: https://doi.org/10.1101/2022.02.07.478973; this version posted February 7, 2022. The copyright holder for this preprint (which was not certified by peer review) is the author/funder, who has granted bioRxiv a license to display the preprint in perpetuity. It is made available under aCC-BY-NC-ND 4.0 International license.

Table 3: qPCR primers.

\begin{tabular}{|c|c|}
\hline Gene Target & Sequence $5^{\prime} \rightarrow 3^{\prime}$ \\
\hline Six2 & AGGAAAGGGAGAACAGCGAGAA \\
\hline \multirow[t]{2}{*}{ Eya1 } & $\begin{array}{l}\text { GGACTGGACGACGAGTGGT } \\
\text { AATTTATGCCTGGCAACTGG }\end{array}$ \\
\hline & CAGACCTCCCACGTTGTTTT \\
\hline \multirow[t]{2}{*}{ Cited2 } & TGCAGAAGCTCAACAACCAG \\
\hline & CTGGTTTGTCCCGTTCATCT \\
\hline Sall1 & AGCCTCAACATTTCCAATCC \\
\hline \multirow[t]{2}{*}{ Wnt9b } & TGGCTTTCGTGAGCATGGAG \\
\hline & AAAGACAGCCACGGTGTGGTAA \\
\hline \multirow[t]{2}{*}{ Fgf 8} & TGTTGCACTTGCTGGTTCTC \\
\hline & CGGCTGTAGAGCTGGTAGG \\
\hline \multirow[t]{2}{*}{$\operatorname{Lim1}(\operatorname{Lhx} 1)$} & CAGTGTCGCCAAAGAGAACA \\
\hline & TGAGACGTTGGCACTTTCAG \\
\hline \multirow[t]{2}{*}{ Wnt4 } & CTGGAGAAGTGTGGCTGTGA \\
\hline & GGACGTCCACAAAGGACTGT \\
\hline \multirow[t]{2}{*}{$G A P D H$} & AGAACATCATCCCTGCATCC \\
\hline & CAGTGAGCTTCCCGTTCAG \\
\hline
\end{tabular}

\section{In Situ hybridization}

The non-radioactive section in situ hybridization technique was performed as described Junttila et al. [63]. The used cDNA probes were Wnt4, Wnt9b, Six2, Eya1 and Cited1 were obtained as gifts from Prof. Thomas Carroll (University of Texas Southwestern, USA).

\section{Flow Cytometry}

Dissected E11.5 kidneys were cultured in a Trowell culture system. After 3 days of culture with or without rmFGF8b, kidneys were dissociated into a single-cell suspension. Cells were fixed with $4 \%$ PFA and permeabilized with BD Cytofix/Cytoperm (BD Biosciences; Cat:\# 554714) as per the manufacturer's instructions. Samples were stained with primary anti-SIX2 antibody for 30 mins on ice, washed, and then stained with secondary Goat anti-rabbit AlexaFluor 488 for 30 mins on ice and washed thoroughly. Samples were scored on FACSCalibur (BD Biosciences). Three biological repeats were carried out for each condition while maintaining the protocol and template for sample acquisition.

\section{Cap mesenchymale quantifications}

Sections of E16.5 $\mathrm{Pax} 8^{\mathrm{Cre}} ; \mathrm{Fg} f 8^{n / c}$, and E11.5 $\mathrm{T}^{\mathrm{Cre}} ; \mathrm{Fg} f 8^{n / c}$ kidneys were cultured for 3 days in Trowell culture, fixed, and stained with anti-SIX2, and anti-TROMA-1 and counterstained with Hoechst 33342 (Thermo Scientific; Cat\# H3570). Imaging was done with Zeiss LSM 780 confocal microscope and samples were analyzed on Zen Blue (2012 edition; Zeiss). The distance between the pair of $S I X 2^{+}$cells closest and most distant to the UB was measured repeatedly along the UB at intervals of one cell length to determine the thickness of the cap mesenchyme. Additionally, the dispersion of NPCs was quantified as the Euclidean distance between NPCs and UB surfaces. Using Bitplane Imaris 9.6.0 and the Imaris modules Measurement Pro and Vantage, NPC positions were quantified using fluorescence intensity-based spot detection and UB surfaces were segmented using fluorescence intensity-based 3D segmentation. To determine the proportions of attached and free/unattached $S I X 2^{+}$ cells in both controls and mutant kidneys, cells were classified as attached when their centroid positions were closer to the UB than twice the median $(17.4 \mu \mathrm{m})$ of all centroid positions of the $S I X 2^{+}$cells in the control kidneys.

\section{Bead assays with NPCs}

A sphere forming assay was modified to induce cell motility in response to FGF8. Metanephric mesenchyme cells were dissociated into a single-cell suspension and an equal amount of cells were divided and mixed with Matrigel. BSA soaked or FGF8 $(100 \mu \mathrm{g} / \mu \mathrm{l})$ soaked agarose blue beads (Affi-Gel Blue Gel, Bio-Rad Cat\#1537302) were carefully placed in individual wells of the 4 Chamber $35 \mathrm{~mm}$ glass-bottom dish (Cellvis, Cat \#D35C4-20-0-N). The Matrigel cell mixture was carefully applied to the surface of the beads and placed in a pre-equilibrated microscopic chamber maintained at $37^{\circ} \mathrm{C}$ and $5 \% \mathrm{CO}_{2}$. Timelapse was performed with Leica SP8 falcon 20X water immersion lens for 24hrs. Cells were tracked using the Imaris (v9.6; BitPlane, South Windsor, CT, USA) cell tracking functionality. Cell tracks from different samples $(\mathrm{n}=5$ each) were pooled and analyzed using the $\mathrm{R}$ package CelltrackR [64].

\section{Modelling}

Our model utilizes a cell-based Lattice-Boltzmann ImmersedBoundary simulation framework for morphogenetic problems [66].

\section{Setup}

We simulated mesenchymal condensation within a $150 \mu \mathrm{m}^{2}$ section of the nephrogenic niche containing randomly dispersed NPCs and a flat patch of ureteric epithelium for an interval of 12 hours, corresponding to embryonic days E10.5 to E11 (Figure 5D, (Supplementary Movie 3). The model represents the dynamics of FGF8, SHH and WNT11 concentrations by the following differential equations:

$$
\begin{aligned}
\partial_{t}[\mathrm{FGF} 8] & =D \Delta[\mathrm{FGF} 8]+\rho_{\mathrm{FGF} 8} H^{S-}([\mathrm{SHH}])-\delta_{\mathrm{FGF} 8} \\
\partial_{t}[\mathrm{SHH}] & =D \Delta[\mathrm{SHH}]+\rho_{\mathrm{SHH}}-\delta_{\mathrm{SHH}} \\
\partial_{t}[\mathrm{WNT} 11] & =D \Delta[\mathrm{WNT} 11]+\rho_{\mathrm{WNT} 11}-\delta_{\mathrm{WNT} 11}
\end{aligned}
$$

$\partial_{t}$ is the time derivative, $D$ is the diffusion coefficient, $\Delta$ denotes the Laplacian operator , $\rho, \delta$ are the production and degradation rates and $H^{S-}$ is the shifted Hill function. Parameter values are shown in Table 4.

\section{Measurements}

At the end of each simulation, the distance of all NPC centroids to the centroid of the ureteric epithelium was measured. All data were pooled and visualized as a boxplot (Figure 5C) using $\mathrm{R}$ [67]. The significance level was determined based on a Wilcoxon signed-rank test and added to the boxplot.

\section{Cells}

Cells are represented by highly resolved 2D polygonal geometries with a cortical tension established by elastic forces between GeometryNodes [66]. Similarly, cell adhesion is realized by elastic forces between neighbouring cells. GeometryNodes are added or removed when the distance between GeometryNodes, i.e. cell size, changes. Similarly, adhesions are created or removed based on a distance threshold between intercellular GeometryNodes. The cells are immersed in a Newtonian fluid and no-flux boundary conditions are imposed on the domain boundaries. 
Table 4: Parameter values for the simulation of mesenchymal condensation in the nephrogenic niche. 1 length unit of the simulation box corresponds to half a micron, i.e. $\Delta x=\frac{0.5 \mu m}{1 \mathrm{LB} \text { length }}$ and $2 \cdot 10^{5}$ iterations correspond to 12 hours of developmental time, i.e. $\Delta t=\frac{12 \mathrm{~h}}{2 \cdot 10^{5} \text { iterations }}=\frac{0.216 \mathrm{~s}}{\text { iteration }}$. The diffusion coefficient $D$ of the morphogens is related to the LB relaxation time $\tau$ via $D=\frac{1}{3}\left(\tau-\frac{1}{2}\right) \cdot \frac{\Delta x^{2}}{\Delta t}[65]$. The gradient length $\lambda=\sqrt{D / d}$ of an exponential gradient $c(x)=c_{0} e^{-x / \lambda}$ is the distance at which the concentration has decreased to $c(\lambda)=c_{0} / e$. []$_{c e l l}$ is the median intracellular concentration. Mass source strength as well as production and degradation rates refer to the PhysicalNodes which represent the discrete grid on which the fluid and the morphogens live [65]. The area of an NPC or an epithelial cell comprises a few hundred PhysicalNodes; the simulation box comprises exactly $300 \cdot 300$ PhysicalNodes. Morphogen dynamics are described above, under Setup.

\begin{tabular}{|c|c|c|c|}
\hline \multirow{2}{*}{$\frac{\text { Solver }}{\text { Cell Growth }}$} & Parameter description & Value [LB units] & Value [SI units] \\
\hline & $\begin{array}{l}\text { BioSolver application rate } \\
\text { mass source strength }\end{array}$ & $\begin{array}{l}1: 1 \\
6 \cdot 10^{-6}\end{array}$ & $\mathrm{~N} / \mathrm{A}$ \\
\hline Cell Boundary Tension & $\begin{array}{l}\text { BioSolver application rate } \\
\text { Hookean spring constant UB - NPCs }\end{array}$ & $\begin{array}{l}1: 10 \\
10^{-3}-5 \cdot 10^{-4}\end{array}$ & $\mathrm{~N} / \mathrm{A}$ \\
\hline Cell Junction & $\begin{array}{l}\text { BioSolver application rate } \\
\text { junction search radius UB - NPCs } \\
\text { intercellular junction length } \\
\text { Hookean spring constant UB - NPCs }\end{array}$ & $\begin{array}{l}1: 10 \\
1.0-2.0 \\
0.3 \\
10^{-2}-10^{-3}\end{array}$ & $\begin{array}{l}0.5 \mu m-1 \mu m \\
0.15 \mu m \\
\text { N/A }\end{array}$ \\
\hline Cell Motility & $\begin{array}{l}\text { BioSolver application rate } \\
\text { normal velocity dist. } \mathcal{N}(0, \sigma)\end{array}$ & $\sigma: \widetilde{[\mathrm{Fgf} 8}_{\text {cell }} 10^{-3}$ & $\{1, \ldots, 10\} \frac{\mu m}{h}$ \\
\hline Cell Motility (Wnt11) & $\begin{array}{l}\text { BioSolver application rate } \\
\text { uniform velocity dist. } p(x \mid 0, b)\end{array}$ & $\begin{array}{l}1: 1 \\
b=[\widetilde{\mathrm{Wnt} 11}]_{\mathrm{cell}} 10^{-4}\end{array}$ & $\{0.1, \ldots, 1\} \frac{\mu m}{h}$ \\
\hline \multirow[t]{3}{*}{ Fgf8 } & CDESolver application rate & $1: 1$ & \\
\hline & $\begin{array}{l}\text { diffusion coefficient } D_{\mathrm{Fgf8}} \\
\text { production rate } \rho_{\mathrm{Fgf8}} \\
\text { degradation rate } \delta_{\mathrm{Fgf8}} \\
\text { gradient length } \lambda_{\mathrm{Fgf8}}\end{array}$ & $\begin{array}{l}\tau=2.0 \\
\{2,3,4\} \cdot 10^{-3} / \text { iteration } \\
10^{-3} / \text { iteration } \\
22.44\end{array}$ & $\begin{array}{l}0.579 \frac{\mu m^{2}}{s} \\
\{6.9,13.9,74.1\} \cdot 10^{-3} / \mathrm{s} \\
4.6 \cdot 10^{-3} / \mathrm{s} \\
11.22 \mu \mathrm{m}\end{array}$ \\
\hline & repression $H^{S-}$ & $1 /\left(1+\left(\frac{[\mathrm{SHH}]}{100}\right)^{2}\right)$ & $\mathrm{N} / \mathrm{A}$ \\
\hline \multirow[t]{2}{*}{$\mathrm{SHH}$} & CDESolver application rate & $1: 1$ & \\
\hline & $\begin{array}{l}\text { diffusion coefficient } D_{\mathrm{SHH}} \\
\text { production rate } \rho_{\mathrm{SHH}} \\
\text { degradation rate } \delta_{\mathrm{SHH}} \\
\text { gradient length } \lambda_{\mathrm{SHH}}\end{array}$ & $\begin{array}{l}\tau=2.0 \\
2 \cdot 10^{-3} / \text { iteration } \\
5 \cdot 10^{-4} / \text { iteration } \\
31.74\end{array}$ & $\begin{array}{l}0.579 \frac{\mu m^{2}}{s_{3}} \\
9.3 \cdot 10^{-3} / s \\
2.3 \cdot 10^{-3} / \mathrm{s} \\
15.87 \mu \mathrm{m}\end{array}$ \\
\hline \multirow[t]{2}{*}{ Wnt11 } & CDESolver application rate & $1: 1$ & \\
\hline & $\begin{array}{l}\text { diffusion coefficient } D_{\mathrm{Wnt} 11} \\
\text { production rate } \rho_{\mathrm{Wnt11}} \\
\text { degradation rate } \delta_{\mathrm{Wnt} 11} \\
\text { gradient length } \lambda_{\mathrm{Wnt11}}\end{array}$ & $\begin{array}{l}\tau=2.0 \\
2 \cdot 10^{-3} / \text { iteration } \\
5 \cdot 10^{-4} / \text { iteration } \\
31.74\end{array}$ & $\begin{array}{l}0.579 \frac{\mu m^{2}}{s_{3}} \\
9.3 \cdot 10^{-3} / \mathrm{s} \\
2.3 \cdot 10^{-3} / \mathrm{s} \\
15.87 \mu \mathrm{m}\end{array}$ \\
\hline
\end{tabular}

\section{Morphogens}

Morphogens are produced and degraded within cells, can freely diffuse within the entire domain and through cell boundaries and are advected by motile cells. Parameter values are shown in Table 4.

\section{Cell motility}

Random motility is established by applying $2 \mathrm{D}$ velocities to each GeometryNode, where velocities are picked from a normal distribution whose standard deviation is proportional to the median local FGF8 concentration (Figure 5B). Similarly, a weak attractive force is established by picking positive $1 \mathrm{D}$ velocities (directed towards the UB) from a uniform distribution where the upper bound is proportional to the median local WNT11 concentration.

\section{Acknowledgments}

We thank Ms Paula Haipus, Ms Johanna Kekolahti-Liias, and Ms Hannele Härkman for excellent technical assistance, and Prof Maxime Bouchard for providing Pax $8^{C r e}$, Fgf $8^{\text {Floxed/Floxed }}$, and $\mathrm{Fgf8} 8^{\Delta 2,3 /+}$ and Prof Andy McMahon for $\mathrm{Hoxb} 7^{\mathrm{Cre}}$ mouse line. We also would like to thank Tiina Jokela for collecting the mouse samples and establishing the protocol for genotyping. We would like to thank Dr. Alan O Perantoni and Dr. Mark B Lewandoski for providing us with $T^{C r e} ; F g f 8^{n / c}$ mouse embryonic kidneys. Dr Veli-Pekka Ronkainen is acknowledged for help in setting up the time-lapse imaging, and the Vainio lab for helpful discussions. Marco Meer thanks Harold Gomez for discussions on image analysis and Lisa Conrad for comments on the manuscript. Confocal imaging was conducted at the Light Microscopy Unit of Biocenter Oulu, University of Oulu. This work was funded for Prof Seppo Vainio by the Academy of Finland (206038, 121647, 250900, 260056), Centre of Excellence Grant 2012-2017 of the Academy of Finland (251314), and Tekes BioRealHealth (24302443); for Dr Florence Naillat, by the Academy of Finland post-doctoral Fellowship (243014583), the Foundations: Post Doc Pool (Svenska Kulturfonden) and the Finnish Cultural Foundation (Pekka ja Jukka-Pekka Lylykarin rahasto); for Marco Meer and Prof Dagmar Iber by the SNF Sinergia grant CRSII5_170930.

\section{Competing Interests}

None declared. 
bioRxiv preprint doi: https://doi.org/10.1101/2022.02.07.478973; this version posted February 7, 2022. The copyright holder for this preprint (which was not certified by peer review) is the author/funder, who has granted bioRxiv a license to display the preprint in perpetuity. It is made available under aCC-BY-NC-ND 4.0 International license.

\section{Author Contributions}

AS, SV \& FN conceived the study, AS, AD \& FN carried out the experiments and acquired the data, AS, MM \& FN analyzed the data and wrote the manuscript, MM developed the computational model with help by DI and carried out the simulations, and AS \& MM produced the figures. All authors have read the manuscript and approved it for publication.

\section{Supplementary Material}

Supplementary movies and source code are available as a git repository*

\section{References}

[1] Amrita Das, Shunsuke Tanigawa, Courtney M Karner, Mei Xin, Lawrence Lum, Chuo Chen, Eric N Olson, Alan O Perantoni, and Thomas J Carroll. Stromal-epithelial crosstalk regulates kidney progenitor cell differentiation. Nature cell biology, 15(9):1035, 2013.

[2] Lori L O'Brien. Nephron progenitor cell commitment: Striking the right balance. In Seminars in cell $\&$ developmental biology, volume 91, pages 94-103. Elsevier, 2019.

[3] Leif Oxburgh. Kidney nephron determination. Annual Review of Cell and Developmental Biology, 34(1):427-450, 2018. doi: 10.1146/annurev-cellbio-100616-060647. PMID: 30125139 .

[4] Domenico Ribatti and Marcello Santoiemma. Epithelialmesenchymal interactions: a fundamental developmental biology mechanism. International Journal of Developmental Biology, 58(5):303-306, 2014.

[5] Elena Scarpa and Roberto Mayor. Collective cell migration in development. J Cell Biol, 212(2):143-155, 2016.

[6] Shuvasree SenGupta, Carole A Parent, and James E Bear. The principles of directed cell migration. Nature Reviews Molecular Cell Biology, pages 1-19, 2021.

[7] B Diehn. Terminology of behavioral responses of motile microorganisms. Photochem. Photobiol., 26:559-560, 1977.

[8] Jamie Davies. 11 - The Urinary System. In Richard Baldock, Jonathan Bard, Duncan R. Davidson, and Gillian Morriss-Kay, editors, Kaufman's Atlas of Mouse Development Supplement, pages 139-146. Academic Press, Boston, January 2016.

[9] Alexander N. Combes, James G. Lefevre, Sean Wilson, Nicholas A. Hamilton, and Melissa H. Little. Cap mesenchyme cell swarming during kidney development is influenced by attraction, repulsion, and adhesion to the ureteric tip. Developmental Biology, 418(2):297-306, October 2016. ISSN 0012-1606.

[10] Nils O Lindström, Guilherme De Sena Brandine, Tracy Tran, Andrew Ransick, Gio Suh, Jinjin Guo, Albert D Kim, Riana K Parvez, Seth W Ruffins, Elisabeth A Rutledge, et al. Progressive recruitment of mesenchymal progenitors reveals a time-dependent process of cell fate acquisition in mouse and human nephrogenesis. Developmental cell, 45 (5):651-660, 2018.

[11] Kynan T Lawlor, Luke Zappia, James Lefevre, Joo-Seop Park, Nicholas A Hamilton, Alicia Oshlack, Melissa H Little, and Alexander N Combes. Nephron progenitor commitment is a stochastic process influenced by cell migration. eLife, 8:e41156, 2019.

[12] Thomas J Carroll, Joo-Seop Park, Shigemi Hayashi, Arindam Majumdar, and Andrew P McMahon. Wnt9b plays a central role in the regulation of mesenchymal to

\footnotetext{
*https://git.bsse.ethz.ch/iber/Publications/2022_Meer_NPC_Condensation
}

epithelial transitions underlying organogenesis of the mammalian urogenital system. Developmental cell, 9(2):283-292, 2005.

[13] Antoine Reginensi, Rizaldy P Scott, Alex Gregorieff, Mazdak Bagherie-Lachidan, Chaeuk Chung, Dae-Sik Lim, Tony Pawson, Jeff Wrana, and Helen McNeill. Yap-and cdc42dependent nephrogenesis and morphogenesis during mouse kidney development. PLoS genetics, 9(3):e1003380, 2013.

[14] Aaron C Brown, Sree Deepthi Muthukrishnan, Justin A Guay, Derek C Adams, Dillon A Schafer, Jennifer L Fetting, and Leif Oxburgh. Role for compartmentalization in nephron progenitor differentiation. Proceedings of the National Academy of Sciences, 110(12):4640-4645, 2013.

[15] Lori L O'Brien, Alexander N Combes, Kieran M Short, Nils O Lindström, Peter H Whitney, Luise A CullenMcEwen, Adler Ju, Ahmed Abdelhalim, Odyssé Michos, John F Bertram, et al. Wnt11 directs nephron progenitor polarity and motile behavior ultimately determining nephron endowment. Elife, 7:e40392, 2018.

[16] Hao Li, Peter Hohenstein, and Satu Kuure. Embryonic kidney development, stem cells and the origin of wilms tumor. Genes, 12(2):318, 2021.

[17] Nils O Lindström, Tracy Tran, Jinjin Guo, Elisabeth Rutledge, Riana K Parvez, Matthew E Thornton, Brendan Grubbs, Jill A McMahon, and Andrew P McMahon. Conserved and divergent molecular and anatomic features of human and mouse nephron patterning. Journal of the American Society of Nephrology, 29(3):825-840, 2018.

[18] Kevin Stark, Seppo Vainio, Galya Vassileva, and Andrew P McMahon. Epithelial transformation of metanephric mesenchyme in the developing kidney regulated by wnt- 4 . $\mathrm{Na}$ ture, 372(6507):679, 1994.

[19] Chiara Mari and Paul Winyard. Concise review: understanding the renal progenitor cell niche in vivo to recapitulate nephrogenesis in vitro. Stem cells translational medicine, 4(12):1463-1471, 2015.

[20] Beat Trueb. Biology of fgfrl1, the fifth fibroblast growth factor receptor. Cellular and molecular life sciences, 68(6): 951-964, 2011.

[21] Sijo Mathew, Xiwu Chen, Ambra Pozzi, and Roy Zent. Integrins in renal development. Pediatric nephrology, 27(6): 891-900, 2012.

[22] Satu Kuure and Hannu Sariola. Mouse models of congenital kidney anomalies. Animal Models of Human Birth Defects, pages 109-136, 2020.

[23] Joshua W Mugford, Jing Yu, Akio Kobayashi, and Andrew P McMahon. High-resolution gene expression analysis of the developing mouse kidney defines novel cellular compartments within the nephron progenitor population. Developmental biology, 333(2):312-323, 2009.

[24] Kenneth A Walker, Sunder Sims-Lucas, and Carlton M Bates. Fibroblast growth factor receptor signaling in kidney and lower urinary tract development. Pediatric nephrology, 31(6):885-895, 2016.

[25] Alan O Perantoni, Olga Timofeeva, Florence Naillat, Charmaine Richman, Sangeeta Pajni-Underwood, Catherine Wilson, Seppo Vainio, Lee F Dove, and Mark Lewandoski. Inactivation of fgf8 in early mesoderm reveals an essential role in kidney development. Development, 132(17): 3859-3871, 2005.

[26] Uta Grieshammer, Cristina Cebrián, Roger Ilagan, Erik Meyers, Doris Herzlinger, and Gail R Martin. Fgf8 is required for cell survival at distinct stages of nephrogenesis and for regulation of gene expression in nascent nephrons. Development, 132(17):3847-3857, 2005.

[27] Sung-Ho Huh, Ligyeom Ha, and Hee-Seong Jang. Nephron progenitor maintenance is controlled through fibroblast 
bioRxiv preprint doi: https://doi.org/10.1101/2022.02.07.478973; this version posted February 7, 2022. The copyright holder for this preprint (which was not certified by peer review) is the author/funder, who has granted bioRxiv a license to display the preprint in perpetuity. It is made available under aCC-BY-NC-ND 4.0 International license.

growth factors and sprouty1 interaction. Journal of the American Society of Nephrology, 31(11):2559-2572, 2020.

[28] Frank Costantini and Raphael Kopan. Patterning a complex organ: branching morphogenesis and nephron segmentation in kidney development. Developmental cell, 18(5):698-712, 2010.

[29] Debbie Clements, Hazel C Taylor, Bernhard G Herrmann, and David Stott. Distinct regulatory control of the brachyury gene in axial and non-axial mesoderm suggests separation of mesoderm lineages early in mouse gastrulation. Mechanisms of development, 56(1-2):139-149, 1996.

[30] Eric W Brunskill, Joo-Seop Park, Eunah Chung, Feng Chen, Bliss Magella, and S Steven Potter. Single cell dissection of early kidney development: multilineage priming. Development, 141(15):3093-3101, 2014.

[31] Aaron C. Brown, Derek Adams, Mark de Caestecker, Xuehui Yang, Robert Friesel, and Leif Oxburgh. Fgf/egf signaling regulates the renewal of early nephron progenitors during embryonic development. Development, 138(23):5099 $5112,2011$.

[32] Anneliis Ihermann-Hella, Tsuyoshi Hirashima, Jussi Kupari, Kristen Kurtzeborn, Hao Li, Hyuk Nam Kwon, Cristina Cebrian, Abdul Soofi, Arvydas Dapkunas, Ilkka Miinalainen, et al. Dynamic mapk/erk activity sustains nephron progenitors through niche regulation and primes precursors for differentiation. Stem cell reports, 11(4):912-928, 2018.

[33] Arvydas Dapkunas, Ville Rantanen, Yujuan Gui, Maciej Lalowski, Kirsi Sainio, Satu Kuure, and Hannu Sariola. Simple 3d culture of dissociated kidney mesenchyme mimics nephron progenitor niche and facilitates nephrogenesis wntindependently. Scientific reports, 9(1):1-10, 2019.

[34] Alan O Perantoni, Lee F Dove, and Irina Karavanova. Basic fibroblast growth factor can mediate the early inductive events in renal development. Proceedings of the National Academy of Sciences, 92(10):4696-4700, 1995.

[35] Masuko Katoh and Masaru Katoh. Cross-talk of wnt and fgf signaling pathways at gsk $3 \beta$ to regulate $\beta$-catenin and snail signaling cascades. Cancer biology \& therapy, 5(9): 1059-1064, 2006.

[36] Zeinab Mokhtari, Franziska Mech, Carolin Zitzmann, Mike Hasenberg, Matthias Gunzer, and Marc Thilo Figge. Automated Characterization and Parameter-Free Classification of Cell Tracks Based on Local Migration Behavior. PLOS ONE, 8(12):e80808, December 2013. ISSN 1932-6203. Publisher: Public Library of Science.

[37] Helen P. Makarenkova, Matthew P. Hoffman, Andrew Beenken, Anna V. Eliseenkova, Robyn Meech, Cindy Tsau, Vaishali N. Patel, Richard A. Lang, and Moosa Mohammadi. Differential Interactions of FGFs with Heparan Sulfate Control Gradient Formation and Branching Morphogenesis. Science signaling, 2(88):ra55, September 2009. ISSN 1937-9145.

[38] Young-Kyung Bae, Nathanie Trisnadi, Snehalata Kadam, and Angelike Stathopoulos. The role of fgf signaling in guiding coordinate movement of cell groups: Guidance cue and cell adhesion regulator? Cell adhesion $\&$ migration, 6 (5):397-403, 2012.

[39] Shuizi Rachel Yu, Markus Burkhardt, Matthias Nowak, Jonas Ries, Zdeněk Petrášek, Steffen Scholpp, Petra Schwille, and Michael Brand. Fgf8 morphogen gradient forms by a source-sink mechanism with freely diffusing molecules. Nature, 461(7263):533, 2009.

[40] Pauli Tikka, Moritz Mercker, Ilya Skovorodkin, Ulla Saarela, Seppo Vainio, Veli-Pekka Ronkainen, James P. Sluka, James A. Glazier, Anna Marciniak-Czochra, and Franz Schaefer. Computational Modelling of Nephron Progenitor
Cell Movement and Aggregation during Kidney Organogenesis. bioRxiv, page 2020.01.14.905711, January 2020.

[41] Joshua W Mugford, Petra Sipilä, Jill A McMahon, and Andrew P McMahon. Osr1 expression demarcates a multipotent population of intermediate mesoderm that undergoes progressive restriction to an osr1-dependent nephron progenitor compartment within the mammalian kidney. Developmental biology, 324(1):88-98, 2008.

[42] Jingyue Xu, Han Liu, Joo-Seop Park, Yu Lan, and Rulang Jiang. Osr1 acts downstream of and interacts synergistically with six2 to maintain nephron progenitor cells during kidney organogenesis. Development, 141(7):1442-1452, 2014.

[43] David AD Munro, Peter Hohenstein, and Jamie A Davies. Cycles of vascular plexus formation within the nephrogenic zone of the developing mouse kidney. Scientific reports, 7 (1):1-13, 2017.

[44] Yanfeng Lin, Shaobing Zhang, Marko Rehn, P Itaranta, Juha Tuukkanen, R Heljasvaara, Hellevi Peltoketo, Taina Pihlajaniemi, and Seppo Vainio. Induced repatterning of type xviii collagen expression in ureter bud from kidney to lung type: association with sonic hedgehog and ectopic surfactant protein c. Development, 128(9):1573-1585, 2001.

[45] Xing Chen, Xiao-Ming Hou, You-Fei Fan, Yu-Ting Jin, and Yu-Lin Wang. Sonic hedgehog protein regulates fibroblast growth factor 8 expression in metanephric explant culture from BALB/c mice: Possible mechanisms associated with renal morphogenesis. Molecular Medicine Reports, 14(4): 2929-2936, October 2016. Publisher: Spandidos Publications.

[46] A. Kispert, S. Vainio, L. Shen, D.H. Rowitch, and A.P. McMahon. Proteoglycans are required for maintenance of Wnt-11 expression in the ureter tips. Development, 122 (11):3627-3637, November 1996. ISSN 0950-1991.

[47] Yukako Uchiyama, Masaji Sakaguchi, Takeshi Terabayashi, Toshiaki Inenaga, Shuji Inoue, Chiyoko Kobayashi, Naoko Oshima, Hiroshi Kiyonari, Naomi Nakagata, Yuya Sato, Kiyotoshi Sekiguchi, Hiroaki Miki, Eiichi Araki, Sayoko Fujimura, Satomi S. Tanaka, and Ryuichi Nishinakamura. Kif26b, a kinesin family gene, regulates adhesion of the embryonic kidney mesenchyme. Proceedings of the National Academy of Sciences, 107(20):9240-9245, May 2010.

[48] Xin Sun, Erik N Meyers, Mark Lewandoski, and Gail R Martin. Targeted disruption of fgf8 causes failure of cell migration in the gastrulating mouse embryo. Genes $\mathscr{E}$ development, 13(14):1834-1846, 1999.

[49] Jing Yu, Thomas J Carroll, and Andrew P McMahon. Sonic hedgehog regulates proliferation and differentiation of mesenchymal cells in the mouse metanephric kidney. Development, 129(22):5301-5312, 2002.

[50] Maxime Bouchard, Abdallah Souabni, Markus Mandler, Annette Neubüser, and Meinrad Busslinger. Nephric lineage specification by pax 2 and pax 8 . Genes $\&$ development, 16 (22):2958-2970, 2002.

[51] Simon D Harding, Chris Armit, Jane Armstrong, Jane Brennan, Ying Cheng, Bernard Haggarty, Derek Houghton, Sue Lloyd-MacGilp, Xingjun Pi, Yogmatee Roochun, et al. The gudmap database-an online resource for genitourinary research. Development, 138(13):2845-2853, 2011.

[52] Jingdong Shan, Tiina Jokela, Ilya Skovorodkin, and Seppo Vainio. Mapping of the fate of cell lineages generated from cells that express the wnt4 gene by time-lapse during kidney development. Differentiation, 79(1):57-64, 2010.

[53] Aaron C Brown, Sree Deepthi Muthukrishnan, and Leif Oxburgh. A synthetic niche for nephron progenitor cells. Developmental cell, 34(2):229-241, 2015.

[54] Shunsuke Tanigawa, Atsuhiro Taguchi, Nirmala Sharma, Alan O Perantoni, and Ryuichi Nishinakamura. Selective 
in vitro propagation of nephron progenitors derived from embryos and pluripotent stem cells. Cell reports, 15(4): 801-813, 2016.

[55] Zhongwei Li, Toshikazu Araoka, Jun Wu, Hsin-Kai Liao, Mo Li, Marta Lazo, Bing Zhou, Yinghui Sui, Min-Zu Wu, Isao Tamura, et al. 3d culture supports long-term expansion of mouse and human nephrogenic progenitors. Cell stem cell, 19(4):516-529, 2016.

[56] Erik N Meyers, Mark Lewandoski, and Gail R Martin. An fgf8 mutant allelic series generated by cre-and flp-mediated recombination. Nature genetics, 18(2):136, 1998.

[57] Mandar Deepak Muzumdar, Bosiljka Tasic, Kazunari Miyamichi, Ling Li, and Liqun Luo. A global doublefluorescent cre reporter mouse. genesis, 45(9):593-605, 2007.

[58] Akio Kobayashi, M Todd Valerius, Joshua W Mugford, Thomas J Carroll, Michelle Self, Guillermo Oliver, and Andrew P McMahon. Six2 defines and regulates a multipotent self-renewing nephron progenitor population throughout mammalian kidney development. Cell stem cell, 3(2):169181, 2008.

[59] Philippe Soriano. Generalized lacz expression with the rosa26 cre reporter strain. Nature genetics, 21(1):70-71, 1999.

[60] Ville Veikkolainen, Florence Naillat, Antti Railo, Lijun Chi, Aki Manninen, Peter Hohenstein, Nick Hastie, Seppo Vainio, and Klaus Elenius. Erbb4 modulates tubular cell polarity and lumen diameter during kidney development. Journal of the American Society of Nephrology, 23(1):112$122,2012$.

[61] Stefano A Pileri, Giovanna Roncador, Claudio Ceccarelli, Milena Piccioli, Aspasia Briskomatis, Elena Sabattini, Stefano Ascani, Donatella Santini, Pier Paolo Piccaluga, Ornella Leone, et al. Antigen retrieval techniques in immunohistochemistry: comparison of different methods. The Journal of Pathology: A Journal of the Pathological Society of Great Britain and Ireland, 183(1):116-123, 1997.

[62] Ewelina Fic, Sylwia Kedracka-Krok, Urszula Jankowska, Artur Pirog, and Marta Dziedzicka-Wasylewska. Comparison of protein precipitation methods for various rat brain structures prior to proteomic analysis. Electrophoresis, 31 (21):3573-3579, 2010.

[63] Sanna Junttila, Ulla Saarela, Kimmo Halt, Aki Manninen, Heikki Pärssinen, M Rita Lecca, André W Brändli, Sunder Sims-Lucas, Ilya Skovorodkin, and Seppo J Vainio. Functional genetic targeting of embryonic kidney progenitor cells ex vivo. Journal of the American Society of Nephrology, 26 (5):1126-1137, 2015.

[64] Inge M. N. Wortel, Annie Y. Liu, Katharina Dannenberg, Jeffrey C. Berry, Mark J. Miller, and Johannes Textor. CelltrackR: An $\mathrm{R}$ package for fast and flexible analysis of immune cell migration data. ImmunoInformatics, 1-2: 100003, October 2021. ISSN 2667-1190. doi: 10.1016/j. immuno.2021.100003.

[65] Simon Tanaka. Simulation techniques for mechano-chemical interactions in morphogenesis. PhD thesis, ETH Zurich, 2016.

[66] Simon Tanaka, David Sichau, and Dagmar Iber. LBIBCell: a cell-based simulation environment for morphogenetic problems. Bioinformatics, 31(14):2340-2347, July 2015.

[67] R Core Team. R: A Language and Environment for Statistical Computing. R Foundation for Statistical Computing, Vienna, Austria, 2020. URL https://www.R-project.org/. 
bioRxiv preprint doi: https://doi.org/10.1101/2022.02.07.478973; this version posted February 7, 2022. The copyright holder for this preprint (which was not certified by peer review) is the author/funder, who has granted bioRxiv a license to display the preprint in perpetuity. It is made available under aCC-BY-NC-ND 4.0 International license.

\section{Supplementary Figures}


bioRxiv preprint doi: https://doi.org/10.1101/2022.02.07.478973; this version posted February 7, 2022. The copyright holder for this preprint (which was not certified by peer review) is the author/funder, who has granted bioRxiv a license to display the preprint in perpetuity. It is made available under aCC-BY-NC-ND 4.0 International license.

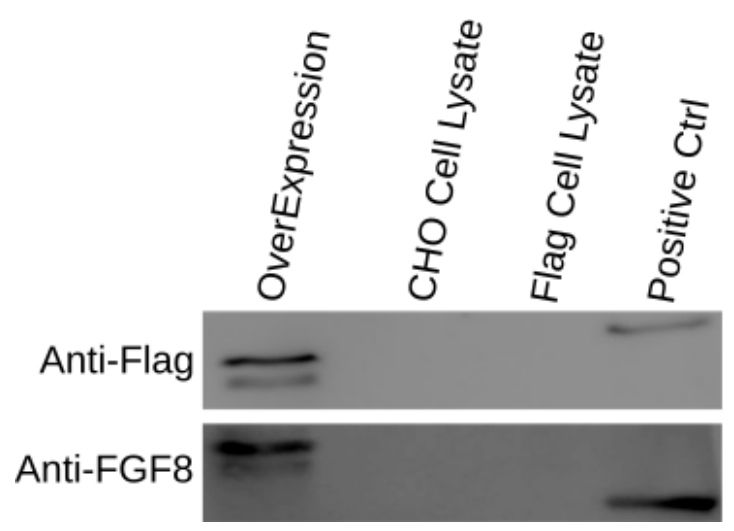

Supplementary Figure 1: The specificity of the FGF8 antibody was measured using flag-tagged FGF8 were expressed in CHO cells. Recombinant mouse FGF8b was used as a positive control.

A

FGF8 treated

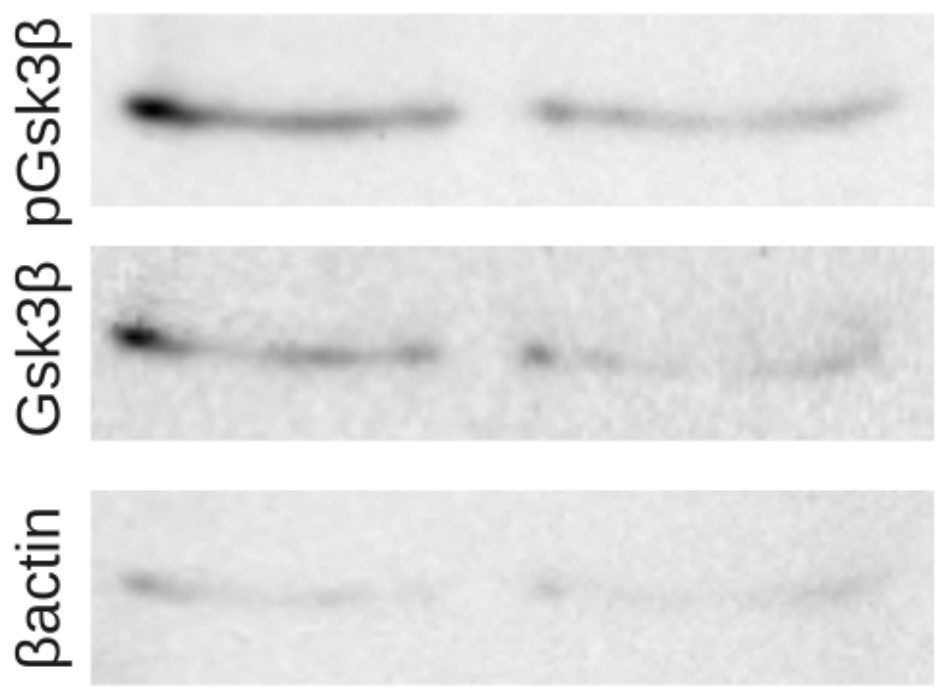

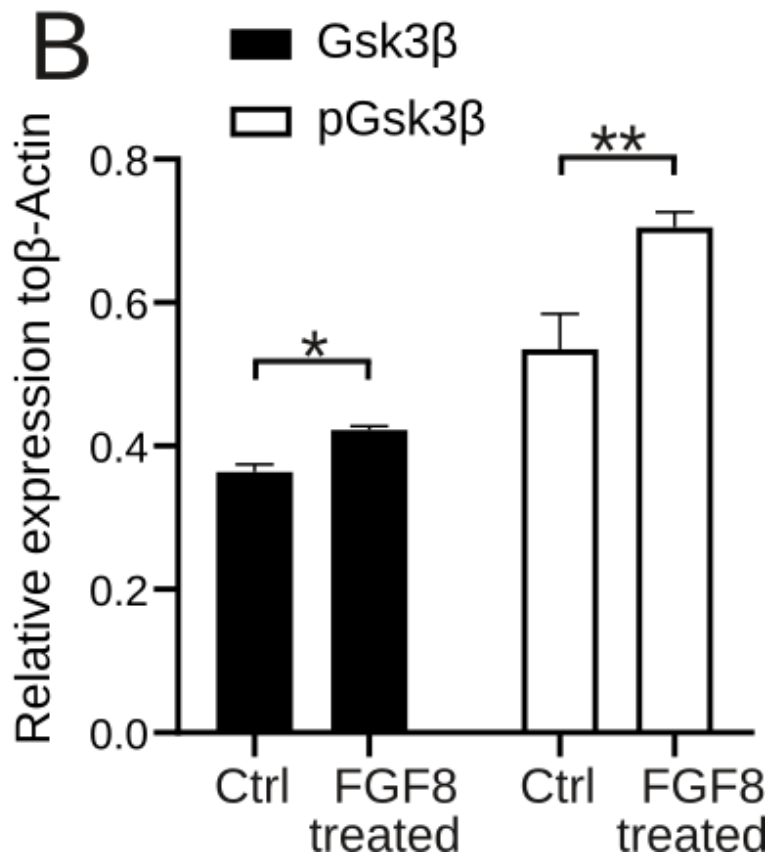

Supplementary Figure 2: Expression of $G S K 3 \beta$ in response to Fgf8b.A) Western blot analysis of phospho- $G S K 3 \beta$ production in response to ectopic FGF8b in nephrosphere culture. B) Relative expression of $G S K 3 \beta$ and phospho- $G S K 3 \beta$. Statistics were performed $(\mathrm{n}=3)$ using Two-way ANOVA. ${ }^{* *} \mathrm{p}<0.023$ and ${ }^{*} \mathrm{p}<0.028$. 

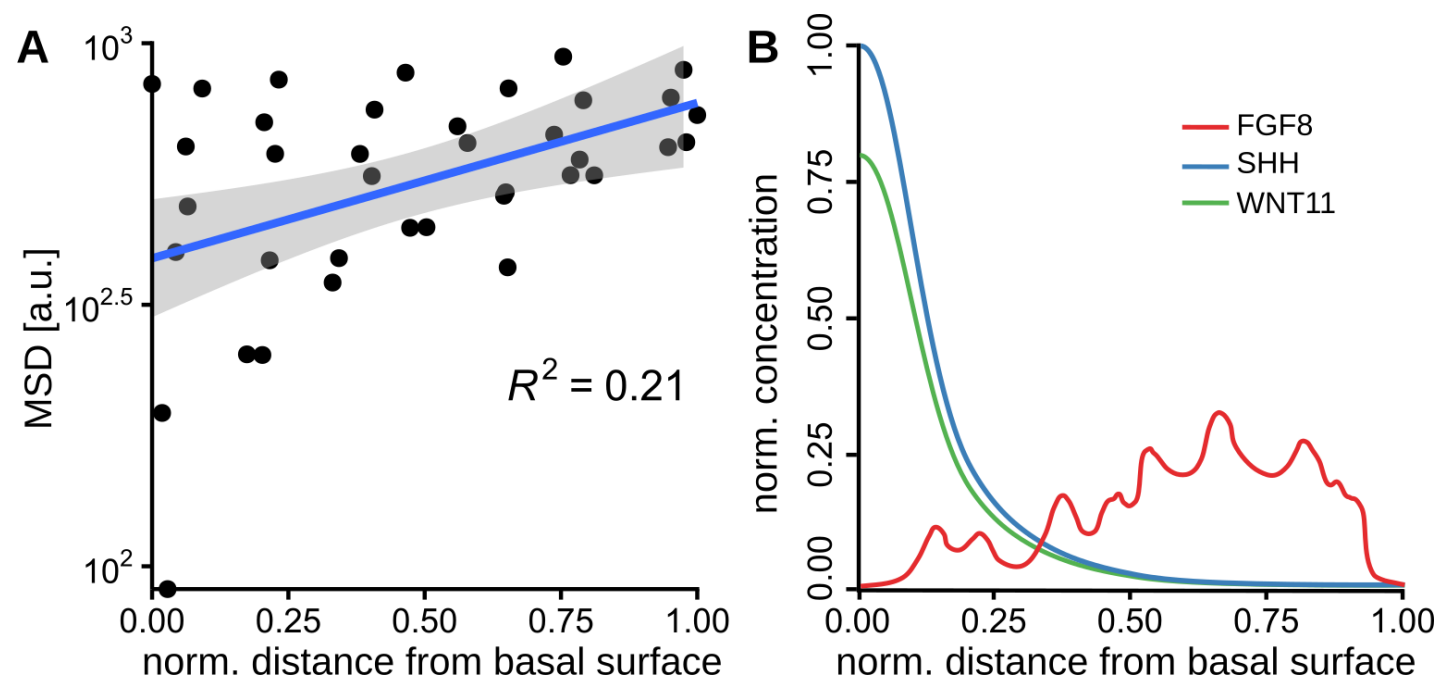

Supplementary Figure 3: Simulated motility and concentration gradients. (A) The observed motility gradient in the simulations quantified by the mean squared displacement (MSD) of each NPC from its initial position with respect to the distance from the basal surface of the ureteric epithelium. Each dot represents the average over $n=20$ simulations of the squared displacement of each NPC from the same initial position. The blue solid line and shadowed region represent a linear regression with confidence interval (95\% confidence level). The low $R^{2}$ indicates the variability of NPC displacements, reflecting the randomness of NPC motility. (B) Example of concentration profiles in the simulations. Curves represent concentration profiles along a line perpendicular to the basal surface of the ureteric epithelium. Concentrations were normalized to the maximum SHH concentration.
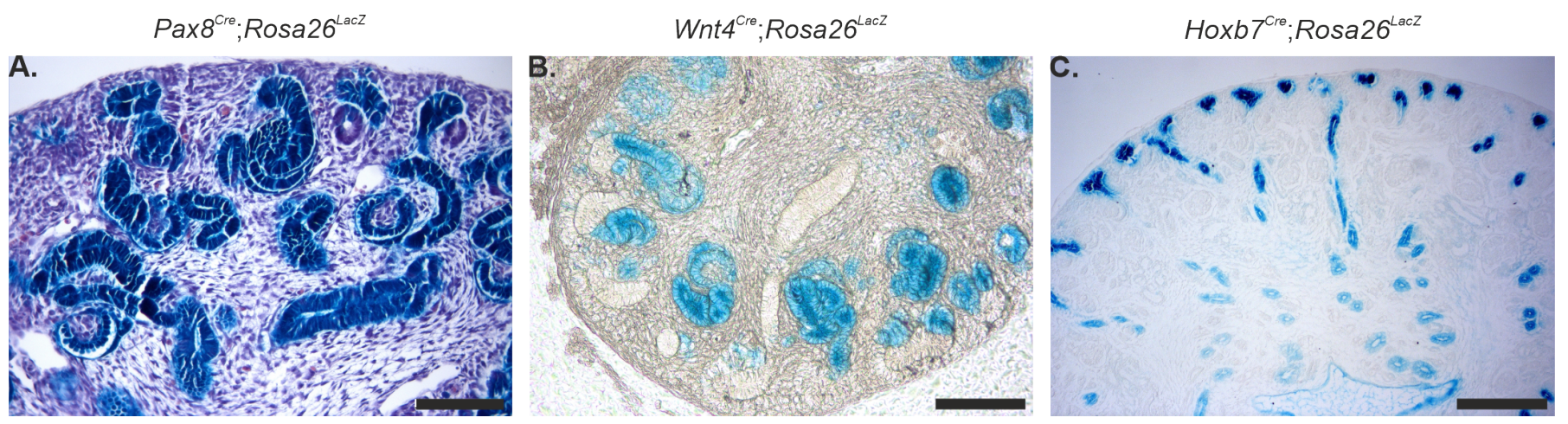

Supplementary Figure 4: X-gal staining after $\beta$-Galactosidase expression due to Cre recombination. A) E14.5 Pax $8^{C r e}$, B) Wnt $4^{\mathrm{Cre}}$ and E16.5 Hoxb7 ${ }^{\mathrm{Cre}}$ mouse kidneys. A) Expression of PAX8 is limited to the UB tip and MM. B) WNT4 expression is observed in PTAs. C) HOXb7 expression is limited UB and no expression was observed in the MM. Scale bar represents $100 \mu \mathrm{m}$. 
bioRxiv preprint doi: https://doi org/10.1101/2022 02.07 .478973 . this version posted February 7,2022 . The copyright holder for this preprint (which was not certified by peer review) is the author/funder, who has granted bioRxiv a license to display the preprint in perpetuity. It is made available under aCC-BY-NC-ND 4.0 International license.

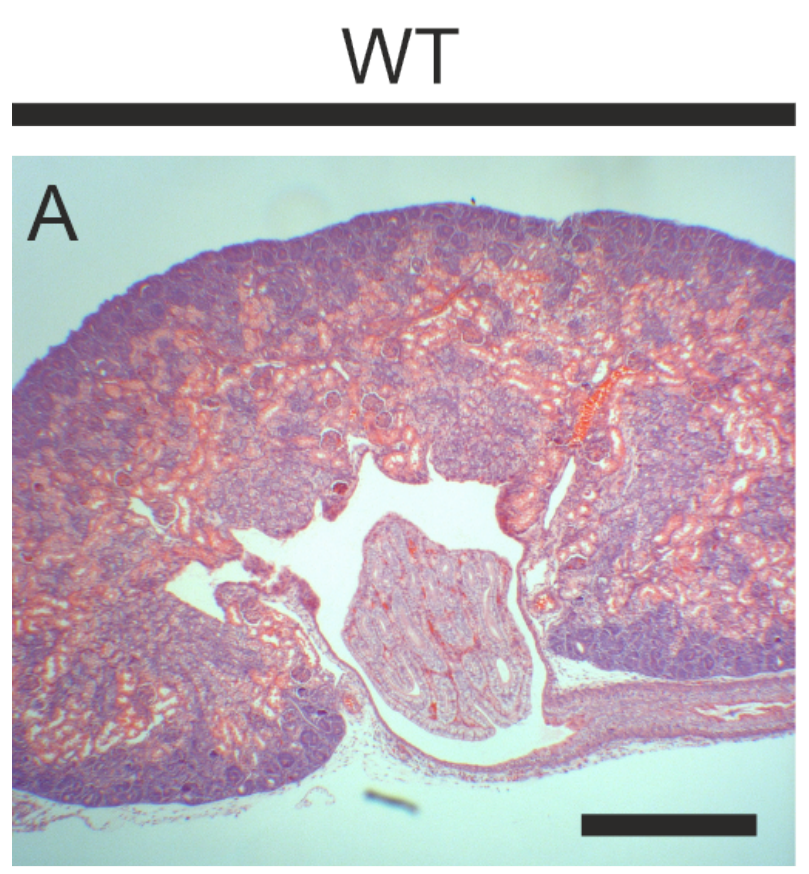

\section{$\mathrm{Hoxb7}^{\mathrm{Cre}} ; \mathrm{Fgf8}^{\mathrm{n} / \mathrm{C}}$}
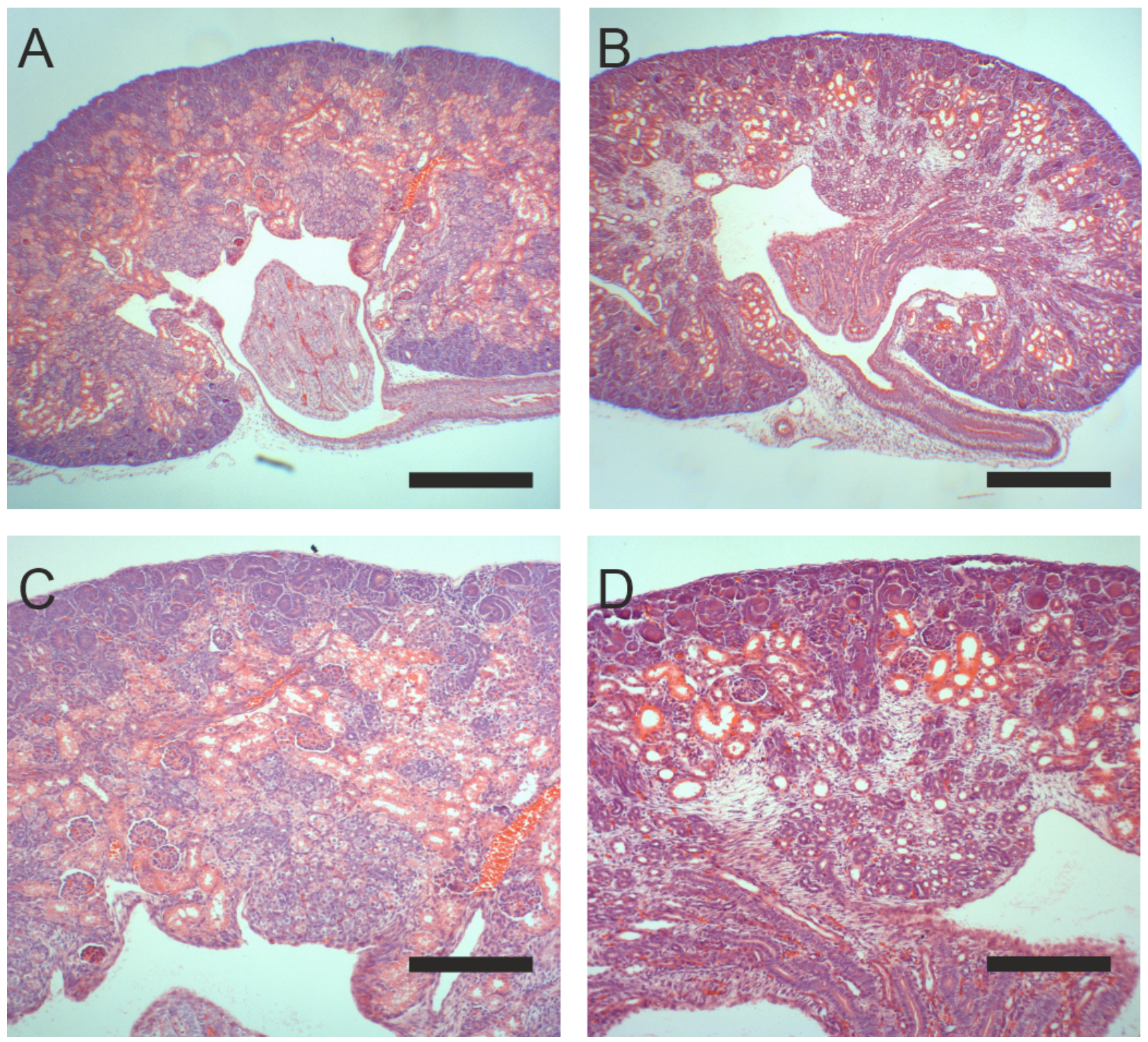

Supplementary Figure 5: Hematoxylin-Eosin staining of (A-C) littermate control (WT) and (B-D) $F g f 8^{n / c} ; H o x b 7^{C r e}$ shows no phenotype. Scale bar represents $100 \mu \mathrm{m}$. 
bioRxiv preprint doi: https://doi.org/10.1101/2022.02.07.478973; this version posted February 7, 2022. The copyright holder for this preprint (which was not certified by peer review) is the author/funder, who has granted bioRxiv a license to display the preprint in perpetuity. It is made available under aCC-BY-NC-ND 4.0 International license.

\section{Supplementary Movies}




\section{Supplementary Movie 1:}

https://git.bsse.ethz.ch/iber/Publications/2022_Meer_NPC_Condensation//blob/main/Video1_spherification_montage.mp4.

24-hour time lapse imaging of in vitro experiments where NPCs were cultured in a 3D matrix. A) NPCs cultured without any additive (control), B) NPCs cultured in FGF2, C) NPCs cultured in FGF8 and D) NPCs cultured in anti-FGF8b antibody. Scale bar represents $50 \mu \mathrm{m}$.

\section{Supplementary Movie 2:}

https://git.bsse.ethz.ch/iber/Publications/2022_Meer_NPC_Condensation//blob/main/Video2_cell_motility_quant.mp4.

Time lapse imaging of in vitro experiments with control beads (A-E) vs. FGF8 soaked beads (F-J), 5 samples each. Dragon tails are shown. Scale bars: $50 \mu \mathrm{m}$.

\section{Supplementary Movie 3:}

https://git.bsse.ethz.ch/iber/Publications/2022_Meer_NPC_Condensation//blob/main/Video3_mesenchymal_condensation_simulations.mp4. Simulations of increasing relative FGF8 concentrations: Scarce, intermediate (2x increased) and high (3x increased). 